\title{
Engineered Geothermal Systems Energy Return On Energy Investment
}

\author{
A.J. Mansure, Geothermal Consultant, \\ ajm@q.com \\ Albuquerque, NM \\ $12 / 10 / 2012$
}

Key Words: energy, EROI, EGS, efficiency, energy investment, energy return, input energy, energy payback, and net energy.

\section{Abstract}

Energy Return On Investment (EROI) is an important figure of merit for assessing the viability of energy alternatives. Too often comparisons of energy systems use "efficiency" when EROI would be more appropriate. For geothermal electric power generation, EROI is determined by the electricity delivered to the consumer compared to the energy consumed to construct, operate, and decommission the facility.

Critical factors in determining the EROI of Engineered Geothermal Systems $\left(E_{G S}{ }^{1}\right.$ ) are examined in this work. These include the input energy embodied into the system. Embodied energy includes the energy contained in the materials, as well as, that consumed in each stage of manufacturing from mining the raw materials to assembling the finished system. Also critical are the system boundaries and value of the energy - heat is not as valuable as electrical energy.

The EROI of an EGS depends upon a number of factors that are currently unknown, for example what will be typical EGS well productivity, as well as, reservoir depth, temperature, and temperature decline rate. Thus the approach developed is to consider these factors as parameters determining EROI as a function of number of wells needed. Since the energy needed to construct a geothermal well is a function of depth, results are provided as a function of well depth. Parametric determination of EGS EROI is calculated using existing information on EGS and US Department of Energy (DOE) targets and is compared to the "minimum" EROI an energy production system should have to be an asset rather than a liability.

\section{Introduction}

EROI analysis is also referred to as Energy Return On Energy Investment. Related terms are energy return, energy ratio, net energy, and energy payback ratio. A primary reason for

\footnotetext{
${ }^{1}$ EGS can stand for either Enhanced Geothermal System (customary DOE usage) or Engineered Geothermal System. An Engineered Geothermal System is an Enahnced Geothermal System where the reservoir is created as a set of discrete flow loops connecting injectors and producers. The energy to construct the reservoir of an Engineered Geothermal System would normally be higher than the energy to enhance the reservoir of an existing sub-economic hydrothermal system. Thus, since an Engineered Geothermal Systems would normally have a lower EROI than an Enhanced Geothermal System, it is the subject of this of this project.
} 
conducting EROI analyses is to identify technologies that are potentially net energy sinks. Standard economic analyses do not necessarily distinguish between net energy producers and sinks especially when there are economic subsidies.

A geothermal power plant involves four energy streams: 1) heat extracted from the reservoir, 2 ) heat rejected to the atmosphere, ${ }^{2} 3$ ) energy to construct, operate, and decommission the facility, and 4) electricity delivered to the customer (Figure 1). Heat extracted from the reservoir and heat rejected to the atmosphere are significant in determining the energy conversion efficiency of the system, but are not explicit factors in determining EROI. Efficiency is the ratio of the energy delivered to the customer to the energy extracted from the reservoir. Whereas, EROI is the ratio of the energy delivered to the customer to the energy consumed to construct, operate, and decommission the facility. Conservation of energy requires that these four streams sum to zero; however, that requirement and efficiency are not sufficient to determine the relationships between the four streams. EROI must also be known. ${ }^{3}$

Past work (Mansure and Blankenship, 2010; and Mansure, 2010) reviewed why EROI is important, methodologies for calculating EROI, as well as, calculations of geothermal EROI done in the 1970's (Herendeen and Plant, $1979 \mathrm{a \& b}$ ). Since the 1970's there have been significant technological advancements that have reduced the energy needed to construct geothermal wells. Also, presumptions made in the 1970's regarding EGS reservoir sustainability have not been justified. Thus an up-to-date determination of EGS EROI is needed.

To be meaningful EROI must consider the value of the input and output energies. Not all energy is of equal value in its usefulness and/or ability to do work. One way the value of energy can formally be accounted for is using available Gibbs free energy or exergy (Patzek, 2004). In addition to the ability to do work, other significant value metrics for comparing energy alternatives include portability and storability. For example, the chemical energy contained in liquid fuel is highly valued, not just for its ability to do work, but also for its portability and storability.

The energy to construct a wellfield depends upon a number of significant factors including the depth of the wells and number of wells. As the depth of the wells increases, the energy needed to construct the well increases. If the power produced does not increase with well depth, that is one has to drill deeper to achieve the same power, then the energy cost increases with no increase in benefit resulting in a lower EROI. The number of wells needed depends on well

\footnotetext{
${ }^{2}$ Most of the "waste" energy is rejected to the atmosphere, but there is also "waste" energy disposed of in the waste materials including during decommissioning. For simplicity in Figure 1 such "waste" energy is considered part of the heat rejected to the atmosphere.

${ }^{3}$ Knowing only either efficiency or EROI and conservation of energy provides two equations, whereas, there are four unknowns. If both efficiency and EROI are known, then the ratios of the energy streams can be determined. The fourth condition needed to determine values of the streams would be the resource or power plant size. That is, if the size of the resource is known, it is possible to design a system with energy flow values that appropriately develops the resource. Efficiency and EROI are functions of resource size; however, provided there is more than minimal resource, the dependence of efficiency and EROI on resource size should not be a major factor.
} 
productivity and reservoir temperature decline rate. Well productivity is function of well flow rate and reservoir temperature.

There has been an increase in well productivity since the 1970's when estimates EGS EROI were based on work at Fenton Hill (Brown, 2009). However, there is still a gap between what has been demonstrated (Soultz for example, Genter et al., 2009) and DOE targets. There is no long term experience on which to base EGS reservoir temperature decline rates. (Annual reservoir temperature decline rate determines how often the wells must be replaced). Thus the approach taken in this work is to determine EROI parametrically as a function of well depth, well flow rate, reservoir temperature, and reservoir temperature decline rate.

A significant concern was "Is EGS EROI high enough to contribute to the balance of society?" This question was addressed by reviewing published work on the "minimum" EROI needed for an energy system to contribute to the balance of society ${ }^{4}$ and by comparing the benefit of investing fossil fuel in developing geothermal systems vs. just consuming the fossil fuel (Mansure, 2011). For example, by comparing investing fossil fuel in developing geothermal power and using the geothermal power in a plug-in electric vehicle vs. burning the diesel fuel in an internal combustion vehicle. This work determined that, if a geothermal system has more than the "minimum" EROI of 3, the energy return would provide a sufficient contribution to the US energy economy to justify investing fossil fuel in developing geothermal systems. With this "minimum" EROI in hand, the parametric determination of EROI allows one to determine what well performances and reservoir temperature decline rates provide an adequate return on energy investment.

The approach to determining EROI presented in this paper is based on process engineering, summing up the energy needed in each step from mining the raw materials to assembling the final product. Two primary sources for information have been used: the DOE sponsored Life Cycle Assessment (LCA) of geothermal energy (Sullivan et al., 2010) and detailed material inventories of well construction developed for this project (updated from Mansure, 2010). The primary additional information needed is the diesel fuel consumed. Fuel is consumed to construct and stimulate the wells and transport the materials to the site. The embodied energies used are those incorporated into the GREET model (Burnham et al., 2006).

A benefit of determining EROI parametrically as a function of well depth and number of wells (well productivity) is that the results presented in this paper can be reinterpreted in terms of hydrothermal resources and direct use of geothermal energy.

\section{Methodology}

Energy must be invested to develop an EGS in the power plant and wellfield. ${ }^{5}$ EROI of a geothermal power production system is determined by the following formula:

\footnotetext{
${ }^{4}$ See discussion of "minimum" EROI in later section.

${ }^{5}$ Energy is needed for the pipelines from the wells to the power plant. In this study the pipelines have been included in the wellfield; that is, the energy to construct $500 \mathrm{~m}$ of pipeline is included in the energy to construct
} 


$$
E R O I=\frac{E_{\text {grid }}}{E_{p p}+E_{w}\left(n_{i}+1\right)(1+r)\left(1+n_{r}\right)},{ }^{6}
$$

where $E_{g r i d}$ is the net energy sold to the grid over the life of the project, $E_{p p}$ is the embodied energy needed to construct the power plant, $E_{w}$ is the embodied energy needed to construct a well, $n_{i}$ is the initial number of EGS injector-producer flow loops, $r$ is the ratio of injectors to producers within a flow loop, and $n_{r}$ the number of times the flow loops have to be replaced. The +1 following $n_{i}$ provides a spare flow loop to maintain system output during wellfield maintenance and outages. From the EGS LCA (Sullivan et al., 2010) $E_{p p}$ is 815TJ for a $50 \mathrm{MW}$ power plant (see discussion in appendix). While $E_{\text {grid }}$ and $n_{i}$ are potentially dependent upon a large number of factors, the significant ones for an EGS are reservoir temperature, production well flow rate, and reservoir temperature decline rate. ${ }^{7} E_{w}$ is dependent upon well depth. $r$ is determined by the strategy employed to develop the flow loops. ${ }^{8}$ Past work on EGS EROI (Herendeen and Plant, $1979 \mathrm{a \& b}$ ) assumed that after 5 years the reservoir temperature will decline sufficiently that the wells would need to be recompleted (restimulated). ${ }^{9}$ Current thinking is that rather than restimulated, the wells will have to be replaced (Tester, 2006). $E_{\text {grid }}$ ,$n_{i}$ and $n_{r}$ have been determined using GETEM (Mines, 2008) using baseline data from Sullivan et al. (2010) and DOE targets (Augustine et al., 2010). Discussion of the use of GETEM can be found in the appendix. $E_{w}$ has been determined as part of this project (see appendix). The relationships between $E_{g r i d}, n_{i}$, and $n_{r}$, and the reservoir properties (depth, temperature, production well flow rate, and temperature decline rate) are nonlinear not independent. That is as depth changes flow rate and thermal losses are affected. Thus it is not possible to present simple trend lines that allow one to calculate EROI for any variation in reservoir properties.

Local geology affects the design of a geothermal well and hence the embodied energy. ${ }^{10}$ However, the affects of well design are much less significant than the change in embodied energy due to well depth. Figure 2 shows the embodied energy as a function of well depth for a number of well designs discussed in the appendix. The embodied energy to construct an EGS well as a function of well depth can be calculated using the following equation (trend line on Figure 2):

$$
E_{w}=\left(1.0625 z^{2}+8.9285 z+12.8\right) \mathrm{TJ},
$$

each well. The length of the pipelines needed should go up as the square or more of the number of wells, however, accounting for that additional input energy would not change the results presented here significantly.

${ }^{6} \mathrm{~A}$ less conservative expression for the denominator would be $E_{p p}+E_{w}\left(n_{i}+1+n_{r}\right)(1+r)$.

${ }^{7}$ For a hydrothermal system or over-pressured EGS resource, temperature decline rate would be replaced by specific enthalpy decline rate.

${ }^{8}$ For a hydrothermal system the number of injectors would be significantly less than for an EGS and the injectors may require less embodied energy to construct than the producers. For an EGS it is assumed that injectors and producers require an equivalent amount of embodied energy.

${ }^{9}$ The energy they assumed required to restimulate the wells was not a significant factor.

${ }^{10}$ See Mansure et al., 2006 for a discussion of the impact of these factors on the related issue of well costs. 
where $z$ is the well depth in $\mathrm{km}$. Discussion of how this equation was developed can be found in the appendix.

Combining equations $1 \& 2$ :

$$
E R O I=\frac{E_{\text {grid }}}{815 \mathrm{TJ}+\left(1.0625 z^{2}+8.9285 z+12.8\right)\left(n_{i}+1\right)(1+r)\left(1+n_{r}\right) \mathrm{TJ}} \cdot{ }^{11}
$$

\section{Results}

EGS EROI ranges from very high to marginal depending upon the properties of the reservoir being developed (Figure 3). Parameters fixed for Figure 3 are reservoir temperature decline rate at $0.5 \%$ and injector to producer ratio at 1 . The figure shows EROI's from a low of less than 3 to over 30. That is a tenfold variation from less than the "minimum" needed EROI (see subsequent section for discussion of "minimum" EROI) to an EROI greater than published average numbers for oil and gas energy resources (Cleveland, 2005). The three sets of curves on Figure 3 are for the depths 2,000m,6,000m and 10,000m. Each set of curves contains data for resource temperatures from $225^{\circ} \mathrm{C}$ to $150^{\circ} \mathrm{C}$ and production well flow rates from $90 \mathrm{~kg} / \mathrm{sec}$ to $30 \mathrm{~kg} / \mathrm{sec}$. Data for a given temperature but varying flow rates are connected and labeled by color. Markers indicate points of actual GETEM calculations.

From a given data point, e.g. $6,000 \mathrm{~m}$ or middle curve set, $225^{\circ} \mathrm{C}$, and $90 \mathrm{~kg} / \mathrm{sec}$, dropping a vertical line shows that $225^{\circ} \mathrm{C}$ and $90 \mathrm{~kg} / \mathrm{sec}$ correspond to $7.6 \mathrm{MW}_{\mathrm{e}}$. Extending a horizontal line shows the EROI is 18.8. Note that for a given temperature and flow rate, c.f. left or right most points on each curve set, the data points of different depths do not line up vertically. This is because the number of wells needed changes with depth, even if all other parameters remain fixed. Overall the Figure 3 shows that EROI is very dependent upon the depth and productivity of the wells.

On Figure 3 the highest set of curves with EROI's ranging from over 30 to about 12 is for $2,000 \mathrm{~m}$ deep wells. $2,000 \mathrm{~m}$ would be a very shallow EGS, one for which reservoir temperatures would not normally be high. So perhaps at this depth a more reasonable range of EROI's would be those for $150^{\circ} \mathrm{C}$ or EROI's from just over 20 to about 12 . Similarly, one would not drill an extra deep or $10,000 \mathrm{~m}$ well unless there was an expectation of high reservoir temperatures and so EROI's below 5 are not as likely as those over 5. EROI's for the $6,000 \mathrm{~m}$ curve set, a reasonable depth target for EGS, range from 19 to 5 . Thus considering likely reservoir depths, temperatures, and production well flow rates, a reasonable range of EGS EROI's is 5 to 20 presuming a $0.5 \%$ reservoir temperature decline rate and an injector to producer rate of 1.

Figure 3 includes data showing the affects of reservoir temperature, production well flow rate, and depth, but not all the potentially significant parameters. In Figure 3 the ratio of injectors to producers and the reservoir temperature decline rate were kept fixed. Figure 4 shows the

\footnotetext{
${ }^{11}$ For an Enhanced Geothermal System that is not made by engineering discrete flow loops such as hydrofracing sub economic hydrothermal system, $\left(n_{i}+1\right)(1+r)\left(1+n_{r}\right)$ would be replaced with the total number of wells needed over the project lifetime.
} 
relative importance of depth, production well flow rate, temperature, injection to producer ratio, reservoir drawdown, ${ }^{12}$ and reservoir temperature decline rate. The baseline data for this sensitivity plot is given in Table 1 . This baseline has an EROI of 14 which is conveniently near the middle of the range noted above. The end points of the input parameters (horizontal axis on Figure 4) for reservoir temperature, production well flow rate, depth, and ratio of injectors to producers were chosen to be reasonable bounds on these parameters. The figure shows that ratio of injectors to producers is not as significant as the parameters included in Figure 3 (depth, flow rate, and temperature). While an upper bound for reservoir drawdown has not been established, Figure 4 shows that this parameter could increase $200 \%$ from the default value in GETEM and still not be as significant as the other parameters. ${ }^{13}$ On the other hand, Figure 4 shows that reservoir temperature decline rate is potentially the most significant factor.

The EROI vs. reservoir temperature decline rate shows a sudden downward jump when the reservoir temperature decline rate increases to more than $100 \%$ of the baseline (Figure 4 ). ${ }^{14}$ This is because at a reservoir temperature decline rate of about $0.63 \%$ the power sales to the grid have declined sufficiently that a replacement set of flow loops is needed. Figure 5 shows the net power sales to the grid for a reservoir temperature decline rate of $0.63 \%$ (average $41.4 \mathrm{MW}_{\mathrm{e}}$ ) vs. a reservoir temperature decline rate of $0.631 \%$ (average $44.49 \mathrm{MW}_{\mathrm{e}}$ ). The power sales to grid jumps up at 25 years when the wells are replaced. An upper bound for reservoir temperature decline rate may be the $3 \%$ assumed in the Future of Geothermal study (Tester, 2006). The DOE goal is to develop techniques to engineer EGS reservoirs such that the flow loops do not have to be replaced (Augustine et al., 2010). With that goal in mind Sullivan et al. (2010) used a reservoir temperature decline rate of 0.5\%. Figure 6 shows the affect of reservoir temperature decline rate on EROI for several reservoir temperatures and flow rates. Fixed parameters in Figure 6 are the depth at $6,000 \mathrm{~m}$ and injector to producer ratio at 1 . The figure shows that the reservoir temperature decline rate at which flow loops must be replaced for the first time is not greatly affected by other parameters and that a reservoir temperature decline rate of $0.5 \%$ is a reasonable target to achieve DOE's goal of not having to replace EGS wells. Figure 6 further shows that for reasonable temperatures and flow rates $\left(>175^{\circ} \mathrm{C} \& 60 \mathrm{~kg} / \mathrm{sec}\right.$ ) the "minimum" EROI needed to be an energy asset (according to Hall et. al 2009) is achievable for $6,000 \mathrm{~m}$ deep reservoirs even if the flow loops have to be replaced twice. ${ }^{15}$

Figure 6 provides insight into the impact of reservoir temperature decline rate at $6,000 \mathrm{~m}$. However, as depth changes EROI changes as a result of the increased energy needed to

\footnotetext{
${ }^{12}$ Reservoir drawdown is a parameter that GETEM uses to calculate the pressure difference in an EGS reservoir between injectors and producers.

${ }^{13}$ If reservoir drawdown were to increase, the concern may be not the impact of extra pumping energy on the EROI, but rather, that the system is more likely to experience cold injection water breakthrough resulting in increased thermal decline.

${ }^{14}$ The sensitivity study baseline temperature decline rate of $0.32 \%$ was chosen to be half way to this jump at $0.63 \%$.

${ }^{15}$ There has been some degree of conservatism (underestimating EGS actual EROI) built into this analysis - the intention being to compensate for minor embodied energies needed to construct, operate, and decommission the facility that have not been explicitly accounted for in this analysis.
} 
construct the wells. Figure 7 shows EROI as a function of reservoir temperature decline rate for a $10,000 \mathrm{~m}$ deep well. The figure shows that for high temperatures and flow rates $\left(225^{\circ} \mathrm{C}\right.$ and $90 \mathrm{~kg} / \mathrm{sec}$ ) even for a reservoir temperature decline rate of $2 \%$ that the EROI is above the "minimum" EROI of 3 that Hall et al. (2009) determined as needed for an energy resource to be an asset. However as the temperature and flow rate decrease, the acceptable reservoir temperature decline rate decreases to about $1 \frac{1}{4} \%$ for $190^{\circ} \mathrm{C}$ and $60 \mathrm{~kg} / \mathrm{sec}$, and decreases to $0.6 \%$ at $175^{\circ} \mathrm{C}$ and $45 \mathrm{~kg} / \mathrm{sec}$. Thus for deep wells increased reservoir temperature decline rate is much more of an issue than for $6,000 \mathrm{~m}$ wells.

\section{An EROI high enough to contribute to the balance of society}

If an energy technology has a low EROI, difficulties in defining the system boundaries ${ }^{16}$ and differences in quality of energy inputs and outputs become significant. There need to be compelling reasons for pursuing a technology with a low EROI. But what is a low EROI? An EROI of one is not adequate. To be useful to society, energy systems must generate more than just the energy required to be self-sustaining, they must support the balance of society.

Hall et al. (2009) initiated the discussion of what is this "minimum" ERO an energy system needs to be an asset rather than a liability. The importance of EROI, according to Hall et al.'s arguments, can be understood by considering the Gross Domestic Product (GDP) and discretionary spending. Roughly $8 \%{ }^{17}$ of the US GDP is spent on energy. According to Hall et al. discretionary spending is about $25 \%$ of the economy. If switching primary energy sources from cheap, high EROI fossil fuels to more expensive, lower EROI alternatives were to require a significant increase of upstream energy investment to deliver the same energy to the consumer, a large portion of discretionary spending would have to be reallocated. Thus, one measure of "are geothermal EROls high enough?" is how will changing from fossil fuel to geothermal energy impact the overall energy economy.

Hall et al.'s (2009) argument for the "minimum" EROI an energy alternative should have is roughly as follows: petroleum is the largest source of primary energy in the US and most of that petroleum is used for transportation. ${ }^{18}$ Hall et al. analysis concluded that 3 barrels of petroleum must be extracted to deliver a barrel of service to the end use transportation customer after considering petroleum consumed in production, refining, distribution, and transportation infrastructure (roads, bridges, etc.). Thus they concluded that the "minimum" EROI an alternative fuel must have to displace fossil fuels as an energy asset, not energy liability, is $3 .^{19}$

\footnotetext{
${ }^{16}$ The system boundaries should be sufficient to encompass all significant energy flows.

${ }^{17}$ EIA (2009) http://www.eia.gov/totalenergy/data/annual/pdf/aer.pdf.

${ }^{18}$ EIA http://www.eia.gov/totalenergy/data/annual/pdf/sec1 8.pdf and EIA http://www.eia.gov/totalenergy/data/annual/pdf/sec5 3.pdf.

${ }_{19}$ More discussion of Hall et al.'s work can be found in Mansure (2011); however, it should be noted that the statement there "If the overall EROI were to double at no change in energy cost, approximately one third of discretionary spending would have to be reallocated." should read "If switching primary energy sources from cheap, high EROI fossil fuels to more expensive, lower EROI alternatives were to require a significant increase of upstream energy investment to deliver the same energy to the consumer, a large portion of discretionary spending would have to be reallocated"
} 


\section{Applying Geothermal Power to Transportation}

One way of assessing the applicability of geothermal power production to transportation is to compare the benefits of burning a barrel of oil as transportation fuel (using it in an internal combustion engine) vs. investing the barrel of oil in developing geothermal power production and using the electricity generated for transportation. The best approach to do this is to use plug-in electric vehicles rather than geothermal power as an energy source for liquid fuel production (Mansure, 2011).

To compare burning a barrel of fuel in an internal combustion engine with investing it in geothermal energy for an electric plug-in vehicle, Saab's 9-3 Sports Combi was used as a basis (Mansure, 2011). This car is currently available with a diesel internal combustion engine and plug-in electric (ePower) prototypes have been displayed at auto shows. ${ }^{20}$ The energy stored in the ePower battery is $6 \%$ of energy in the diesel fuel tank, but the km per kWh is more than four times that of the diesel resulting in a $200 \mathrm{~km}$ range for the ePower prototype or $23 \%$ of the diesel version range. ${ }^{21}$ The battery pack is designed to charge overnight and to have a ten year life time. ${ }^{22}$ Thus while the storability of electric energy in the ePower prototype is enough to go three times the distance an average US car is driven in a day, it is not enough for road trips.

The customary performance metric for the effectiveness of converting liquid fuel into transportation is $\mathrm{km}$ per liter ( $\mathrm{mi} / \mathrm{gal})$. Table 2 compares the effectiveness of various ways using diesel fuel for personal vehicle transportation including internal combustion engines, generating hydrogen for use in fuel cell vehicles, plug-in electric vehicles powered by a central power plant burning diesel, and investing in developing geothermal power for plug-in electric vehicles. The investment in geothermal approach is based on a "minimum" EROI of 3 and a mid-range value of 13 . Details of how these numbers were calculated can be found in Mansure (2011). ${ }^{23}$

\section{Geothermal heating and cooling}

Should a barrel of diesel fuel be burned for heating or invested in extracting geothermal energy? Geothermal energy can be used for heating either by generating electricity or by direct heating. If geothermal generated electricity is used in an electric heater, the benefit is the EROI of the geothermal power generation system which for this study is assumed to be at least 3 or a mid-range value of 13 - that is more than 3 to $12^{24}$ Joules of heat are delivered for each Joule of

\footnotetext{
${ }^{20}$ http://www.saabsunited.com/2011/09/oktoberfest-saab-e-power.html

${ }^{21}$ With Saab's bankruptcy development of the ePower 9-3 Sports Combi beyond prototypes is questionable at this time. However, the significant numbers presented here is supported by specifications for the Tesla model $\mathrm{S}$ which has the same efficiency $(\mathrm{km} / \mathrm{kWh})$ but even longer range (http://www.teslamotors.com/models/features\#/battery).

22 "It can be fully recharged from a domestic mains supply in about three to six hours, depending on depletion status." According to Saab - search for ePower on http://newsroom.saab.com.

${ }^{23}$ Based on an electricity cost of $10 c$ per $\mathrm{kWh}$ and a road tax of $0.78 \mathrm{c} / \mathrm{km}$, the energy cost per $\mathrm{km}$ for the ePower Saab is half the cost of diesel. (This paper is concerned with energy balances not costs. Thus it is assumed that geothermal power is competitive with other electrical power options.)

${ }^{24} 12$ not 13 because of transmission losses between power generation and consumption. According to EIA data electricity transmission losses are $7 \%$ http://tonto.eia.doe.gov/ask/electricity faqs.asp\#electric rates2.
} 
diesel fuel consumed. Note, direct burning diesel in a furnace delivers $~ 0.87$ Joules for each Joule consumed because of the efficiency of furnace heating systems, typically in the range of $78 \%$ to $95 \% .^{25}$

A significantly increased benefit can be obtained by using a geothermal heat pump. A geothermal heat pump with a Coefficient Of Performance (COP) of $3.6^{26}$ using geothermal generated electricity would result in greater than a 10 fold return on energy investment ((EROI of EGS) $\left.* 93 \%{ }^{27} * 3.6\right) .{ }^{28}$ That is investing a Joule of diesel energy in geothermal electricity production to power a geothermal heat pump results in delivering more than 10 Joules of heat. The Joule of diesel fuel could be burnt in a thermal power plant and the resulting electricity used in a electric heater, but in this case the Joule of diesel fuel would only produce 0.31 Joules of electricity after accounting for generation and transmission losses. ${ }^{29}$ When used in an Energy Star rated traditional heat pump with a COP of $2.4,{ }^{30}$ return on the initial Joule of diesel energy would be $0.31 * 2.4=0.74$ Joules or less than $8 \%$ that of geothermal.

A further benefit is the geothermal heat pump can be used for cooling. In this case the benefit for a geothermal heat pump with an Energy Efficiency Ratio (EER - btu/kWh) of $16^{31}$ would be (EROI of EGS) $* 93 \% * 16 * 0.29$ or $>13$ Joules for each Joule of diesel fuel invested For traditional power generation and heat pump the benefit is $0.31^{32} * 12^{33} * 0.29=1$ Joules or less than $9 \%$ that of geothermal. ${ }^{34}$

Since the energy required to construct a geothermal well increases non-linearly with depth, ${ }^{35}$ it is "conservative" to investigate the benefits of geothermal district heating using a deep (6.1 km) EGS well. ${ }^{36}$ Mansure (2011) estimated the energy that can be delivered to the district heating system by a pair of these wells is 22 times the energy needed to construct the wells based on a bottomhole temperature of $225^{\circ} \mathrm{C}$. For shallower wells both the energy to construct the well and the bottomhole temperature should be less and the EROI does not change radically.

${ }^{25}$ American Council for an Energy-Efficient Economy http://www.aceee.org/consumer/heating\#furnaces and Energy Star boiler rating http://www.energystar.gov/index.cfm?fuseaction=find a product.showProductGroup\&pgw code=BO.

${ }^{26}$ Direct Geoexchange (DGX), Energy Star tier 3 Geothermal Heat Pumps Key Product Criteria, http://www.energystar.gov/index.cfm?c=geo heat.pr crit geo heat pumps.

${ }^{27}$ According to EIA data electricity transmission losses are $7 \%$ http://tonto.eia.doe.gov/ask/electricity faqs.asp\#electric rates2.

${ }^{28}$ The energy to construct the heat pump needs to be added to the investment, but that energy has been estimated to be $<<1 \%$ of the heat delivered by the heat pump and thus should be insignificant.

${ }^{29} \mathrm{http}: / / \mathrm{www}$. eia.gov/cneaf/electricity/page/co2 report/co2report.html.

${ }^{30} \mathrm{http}: / /$ www.energystar.gov/index.cfm?c=airsrc heat.pr crit as heat pumps.

${ }^{31}$ Direct Geoexchange (DGX), Energy Star tier 3 Geothermal Heat Pumps Key Product Criteria, http://www.energystar.gov/index.cfm?c=geo heat.pr crit geo heat pumps.

32 http://www.eia.gov/cneaf/electricity/page/co2 report/co2report.html.

33 http://www.energystar.gov/index.cfm?c=airsrc heat.pr crit as heat pumps.

${ }_{34}$ Numbers in previous paper (Mansure 2011) had a unit conversion error.

${ }^{35}$ This is a consequence of the increased number of casing strings and casing diameter required to construct deep wells.

${ }^{36}$ Well design by ThermaSource (Polsky et al., 2009). 
Table 3 summarizes the comparison between traditional heating and cooling vs. geothermal of the benefit that can be delivered starting with one Joule of diesel fuel.

\section{Closing the loop}

One way of minimizing confusion regarding the effect of system boundaries and quality of energy on EROI is to close the loop. That is to use the system output energy as the investment energy for the next generation system. In the case of geothermal energy that means using electricity from one geothermal system to develop the next geothermal production system.

The impact on EGS EROI of closing the loop depends on the mix of material and energy inputs needed for EGS construction. Energy inputs can be a) chemical energy in the raw materials (e.g. energy released while producing coke from coal as part of steel production), b) consumption of fossil fuels (e.g. diesel fuel used by trucks hauling materials to the location), or c) electricity generated from primarily energy sources (Figure 8). Substitution of geothermal power for the raw material chemical energy is impractical. ${ }^{37}$ Substitution of geothermal power for transportation fuel can be difficult as in the case of producing liquid fuel for use in trucks that haul materials to the location. Because of the high exergetic value of electricity, the difficulty is associated with the chemical processes, not the value of geothermal power. Fortunately transportation energy is on the order of only $10 \%$ of the EGS construction energy. Substitution of geothermal power for grid or on location generated electric power does not pose problems. Thus, as shown in Figure 8 the most logical use of geothermal power (dotted line) would be to displace fossil fuels used to generate electricity (dashed line).

Based on the energy needed to develop a $20 \mathrm{MW}$ of EGS power using DOE target (Augustine et al., 2010) well productivity and depletion, closing the loop as shown by the dotted line in Figure 8 would result in a $39 \%{ }^{38}$ reduction in EGS construction energy (Mansure, 2011).

In addition to reducing the energy to construct the system, to determine the impact of closing the loop on EROI one must account for closing the loop consumes some of the output energy. The change in EROI can be calculated as follows:

$$
E R O I_{2}=\frac{E R O I_{1}-f}{(1-f)}
$$

where $\mathrm{EROI}_{1}$ and $\mathrm{EROI}_{2}$ are the EROI before and after closing the loop and $f$ is reduction in input energy, 0.39 for the case above. For an initial EROI of $3^{40}$, the new EROI resulting from closing the loop as shown in Figure 8 is 4.3. For an initial EROI of 13 (middle of the range of EROI's determined above), the new EROI resulting from closing the loop is 20.7. This suggests the

\footnotetext{
37 The same issue exists for other alternative energies that use steel and cement. This is less of an issue for aluminum.

${ }^{38}$ Since the reduction is larger for the wellfield than the power plant, as the number of wells increases, the benefit of closing the loop increases, but not significantly.

39 If the impact of closing the loop were an increase, rather than a decrease, in the energy to construct the system, $f$ would be negative.

${ }^{40}$ The "minimum" EROI needed for an energy alternative to be an asset (according to Hall et. al 2009).
} 
impact of closing the increases geothermal EROI's; however, the potential impact of synthesizing transportation fuel (middle fuel stream in Figure 8 ) has not been considered. ${ }^{41}$

\section{Conclusion}

It takes energy to acquire more energy. Thus as new sources of energy are developed, it is important that they have a high EROI. High enough that they don't require energy subsidies, high enough to decrease dependency on existing energy sources rather than accelerating their depletion. Currently most countries depend upon fossil fuel, petroleum in particular, as their primary energy source. Thus the question, how does a potentially new source of energy compare with petroleum? An EORI of 3 to the end use consumer has been proposed as the value a new energy system must achieve to substitute for petroleum without requiring an energy subsidy. Hall et al. (2009) proposed this "minimum" needed EROI value by considering the downstream consumption of petroleum products necessary to provide the infrastructure (refining, distribution, roads, bridges, etc.) and fuel than runs the US transportation system.

While a wide range of EGS EROI's are possible, it is anticipated for EGS reservoirs with reasonable characteristics (depth, temperature, flow rate, and reservoir temperature decline rate) that EROI's will be achieved significantly above the minimum EROI required for EGS to contribute to the energy economy as an asset slowing the depletion of fossil fuels. Of these characteristics reservoir temperature decline rate is most challenging both in establishing bounds and analyzing the impact. Cost of EGS is outside the scope if this work, however, because of the correlation between costs, material consumption, and embodied energy, it can be concluded from this work that it is unlikely that a cost competitive EGS would not have a high EROI.

\section{Closing Remark}

Geothermal resources are much simpler than many of the other energy alternatives (e.g., they don't have the complexity of soil depletion of bio-fuels, they integrate into the existing infrastructure without storage, they don't produce long term hazardous waste, etc.), so while the system boundaries used in this study do not encompass every energy impact of developing and decommissioning an EGS system, they do not omit significant impacts and should be sufficient to calculate EROI values that are as complete as other energy alternatives. That is a result of the nature of a geothermal system - a simple heat engine.

\section{Acknowledgements}

The assistance of Bob Swanson of ThermaSource and Ron Tate of ChemTech Services in developing the material inventory used for the baseline well and the assistance of Randy Badger of Hydro Resources in supplying information on electrical submersible pumps (ESP) are gratefully acknowledged. Argonne National Laboratory's assistance in providing reference values for the energy embodied into manufactured materials has been invaluable. Access to Sandia National Laboratories' well drilling data is gratefully acknowledged. Both Argonne National Laboratory and Sandia National Laboratory have provided guidance for this work. This

\footnotetext{
${ }^{41}$ Other energy alternatives would be subject to the same issue.
} 
work was performed under contract to the US Department of Energy, Geothermal Programs Office, grant DE-EE0002740.

\section{References}

Asanuma, H., Y. Kumano, T. Izumi, N. Soma, H. Kaieda, K. Tezuka, D. Wyborn, and H. Niitsuma, 2004, "Passive Seismic Monitoring of a Stimulation of HDR Geothermal Reservoir at Cooper Basin, Australia," Technical Program Expanded Abstracts 23:556-559, Society of Exploration Geophysics.

Augustine, C., K.R. Young, and A. Anderson, 2010, "Updated U.S. Geothermal Supply Curve," National Renewable Energy Laboratory, NREL/ CP-6A2-47458.

Baria, R., R. Jung, T. Tischner, J. Nicholls, S. Michelet, B. Sanjuan, N. Soma, H. Asanuma, B. Dyer and J. Garnish, 2006, "Creation Of An HDR Reservoir At 5000 M Depth At The European HDR Project," Proceedings Thirty-First Workshop on Geothermal Reservoir Engineering, Stanford University, SGP-TR-179.

Bossel, U., 2006, “Does a Hydrogen Economy Make Sense?," Proceedings of the IEEE, V 94(10), 1826-1837.

Brown, D. W., 2009, "Hot Dry Rock Geothermal Energy: Important Lessons from Fenton Hill," Proceedings Thirty-Forth Workshop on Geothermal Reservoir Engineering, Stanford University, SGP-TR-187.

Burnham, A., M. Wang, and Y. Wu, 2006, "Development and Applications of GREET 2.7 - The Transportation Vehicle Cycle Model," Argonne National Laboratory Report ANL/ESD/06-5, Argonne, IL. http://www.transportation.anl.gov/modeling simulation/GREET/publications.html.

Cladouhos, T. T., M. Clyne, M. Nichols, S. Petty, W. L. Osborn, and L. Nofziger, 2011, "Newberry Volcano EGS Demonstration Stimulation Modeling," Geothermal Resources Council Transactions, V 35, p 317-322.

Clark C.E., C. Harto, J.L. Sullivan, and M. Wang, 2011, "Water Use in the Development and Operations of Geothermal Power Plants," Argonne National Laboratory, ANL/ESV/R-10/5 http://web.anl.gov/renewables/pdfs/ANL EVS R-10 5.pdf.

Cleveland, C., 2005, "Net energy from the extraction of oil and gas in the United States," Energy 30 (2005) 769-782, http://www.elsevier.com/locate/energy

Dahmus, J.D. and T.G. Gutowski, 2004, “An Environmental Analysis of Machining," Proceedings of IMECE2004, 2004 ASME International Mechanical Engineering Congress and RD\&D Expo, IMECE2004-62600.

Entingh, D. J. and G.L. Mines, 2006, "A Framework for Evaluating Research to Improve U.S. Geothermal Power Systems," Geothermal Resources Council Transactions, V. 30, p 741-746.

EPA 821-R-93-003 referencing Offshore Operators Committee, 1981, "Alternate Disposal Methods for Muds and Cuttings, Gulf of Mexico and Georges Bank," Offshore Rulemaking Record, V 28. 
Genter, A., D. Fritsch, N. Cuenot, J. Baumgärtner, J. Graff, 2009, "Overview of the Current Activities of the European EGS Soultz Project: from Exploration to Electricity Production," Proceedings Thirty-Forth Workshop on Geothermal Reservoir Engineering, Stanford University, SGP-TR-187.

Hall, C.A.S., S. Balogh, and J.R. Murphy, 2009, "What is the Minimum EROI that a Sustainable Society Must Have?," Energies, V 2, p 25-47.

Helms, H., M. Pehnt, U. Lambrecht and A. Liebich, 2010, "Electric vehicle and plug-in hybrid energy efficiency and life cycle emissions," 18th International Symposium Transport and Air Pollution, Session 3: Electro and Hybrid Vehicles, Dübendorf, Switzerland, p113-124.

Herendeen R.A. and R.L. Plant, 1979a, "Energy Analysis of Four Geothermal Technologies," Energy, V 6, p. 73.

Herendeen, R.A. and R.L. Plant, 1979b, "Energy Analysis of Geothermal-Electric Systems." Energy Research Group Office of Vice Chancellor for Research, University of Illinois, UrbanaChampaign, http://www.osti.gov/geothermal/.

Mansure, A.J., 2010, "Review of Past Geothermal Energy Return On Investment Analyses," Geothermal Resources Council Transactions, V 34, p 91-98.

Mansure, A.J., 2011, "Are Geothermal Energy Returns On Investment High Enough?," Proceedings Thirty-Sixth Workshop on Geothermal Reservoir Engineering, Stanford University, SGP-TR-191.

Mansure, A.J., and D.A. Blankenship, 2010, "Energy Return On Energy Investment, an important figure-of-merit for assessing energy alternatives," Proceedings Thirty-Fifth Workshop on Geothermal Reservoir Engineering, Stanford University, SGP-TR-188.

Mansure, A.J., S.J. Bauer, and B.J. Livesay, 2005. "Geothermal Well Cost Analyses 2005," Geothermal Resources Council Transactions, V 29.

Mansure, A.J., S.J. Bauer, B.J. Livesay, and S. Petty, 2006, “Geothermal Well Cost Analyses 2006" Geothermal Resources Council Transactions, V 30.

Michelet, S., and M.N. Toksöz, 2006, "Fracture Mapping in the Soultz-sous-Forêts Geothermal Field from Microearthquake Relocation," Earth Resources Laboratory Consortium Report.

Mines, G., 2008, "Geothermal Electricity Technologies Evaluation Model, DOE Tool For Assessing Impact Of Research On Cost Of Power," Proceedings, Thirty-Third Workshop on Geothermal Reservoir Engineering, Stanford University, SGP-TR-185.

Orazzini, S., R. Kasirin, G. Ferrari, A. Bertini, I. Bizzocchi, R. Ford, Q. Li, and M. Zhang, 2011. "New Roller Cone Bit Technology for Geothermal Application Significantly Increases OnBottom Drilling Hours," Geothermal Resources Council Transactions, V 35.

Patzek, T.W., 2004, "Thermodynamics of the Corn-Ethanol Biofuel Cycle," Critical Reviews in Plant Sciences, V 23(6), 519-567, http://gaia.pge.utexas.edu/papers/CRPS416-Patzek-Web.pdf. 
Polsky, Y., L. Capuano Jr., J. Finger, M. Huh, S. Knudsen, A.J. Mansure, D. Raymond, and R.J. Swanson, 2008, "Enhanced Geothermal Systems (EGS) Well Construction Technology Evaluation Report," Sandia Report SAND2008-7866.

Polsky, Y., A.J. Mansure, D. Blankenship, R.J. Swanson, and L.E. Capuano, Jr., 2009, "Enhanced Geothermal Systems (EGS) Well Construction Technology Evaluation Synopsis," Proceedings Thirty-Fourth Workshop on Geothermal Reservoir Engineering, Stanford University, SGP-TR187.

Sullivan, J.L, C.E. Clark, J. Han, and M. Wang, 2010, "Life Cycle Analysis of Geothermal Systems in Comparison to other Power Systems," Argonne National Laboratory, ANL/ESD/10-5.

Tester, J.W., 2006, "The Future of Geothermal Energy: Impact of Enhanced Geothermal Systems (EGS) on the United States in the 21st Century," Massachusetts Institute of Technology, http://geothermal.inel.gov/publications/future of geothermal energy.pdf.

Zimmermann, G., I. Moeck, and G. Blocher, 2009, "Cyclic Waterfrac Stimulation to Develop an Enhanced Geothermal System (EGS) - Conceptual Design and Experimental Results," Geothermics, V 39(1):59-69, March. 


\section{Figures}

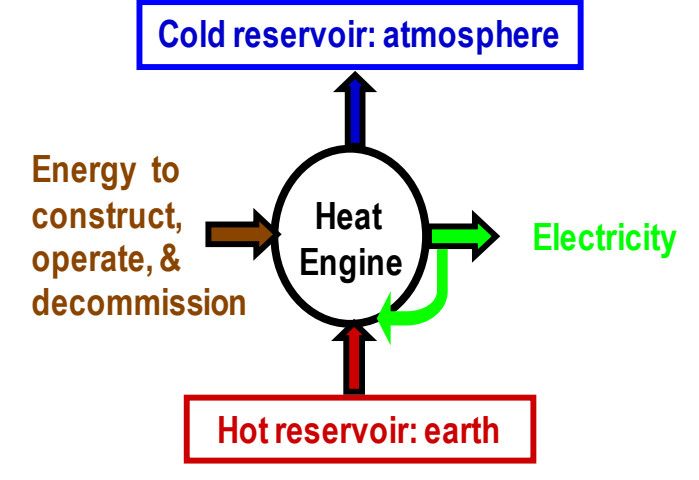

Figure 1: Geothermal heat engine converting energy, raw materials, and heat from the earth into electricity. ${ }^{42,43}$

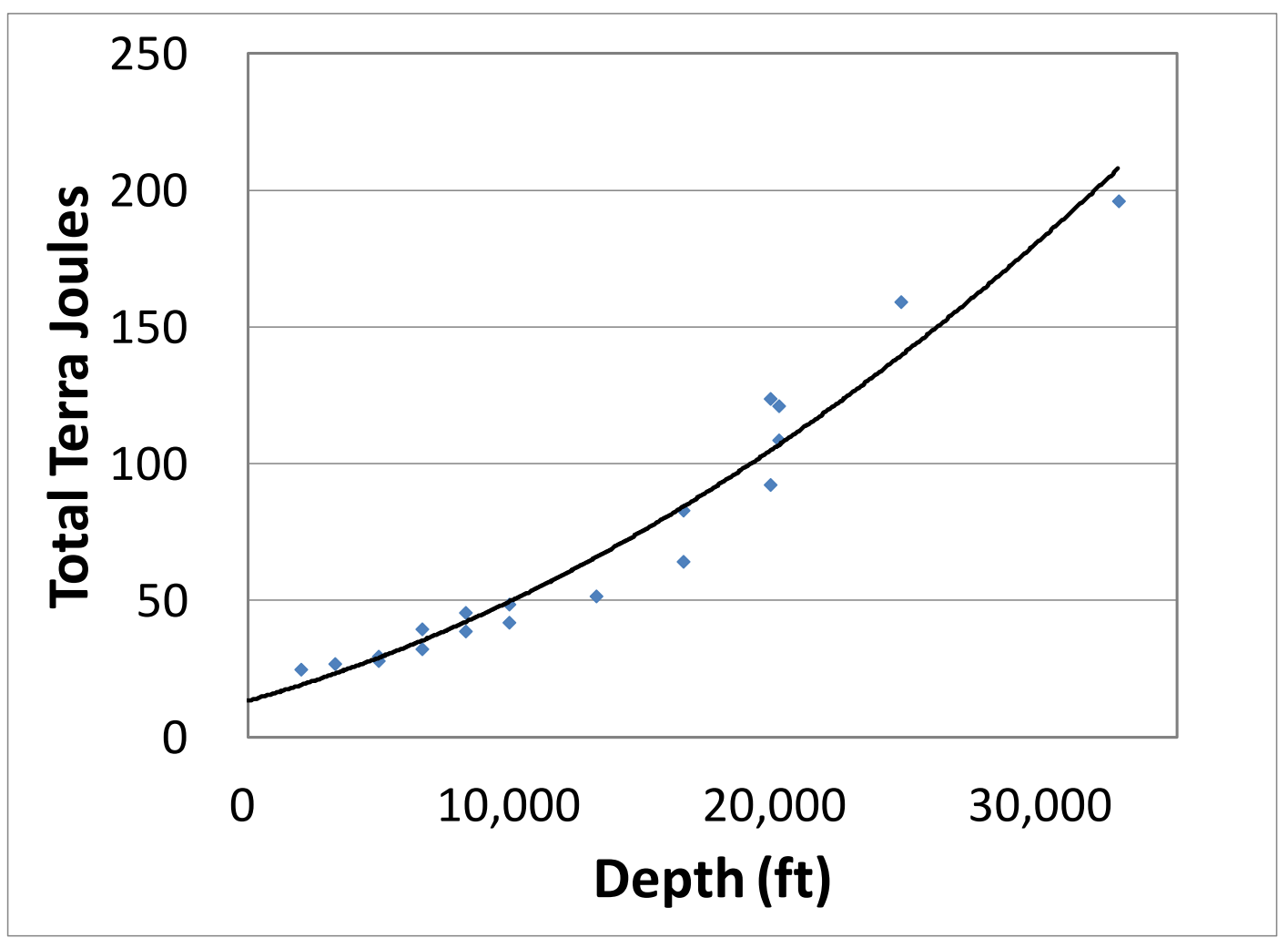

Figure 2: Embodied energy as a function of well dept.

\footnotetext{
${ }^{42}$ The figure shows a feedback loop from the electricity produced to heat in the system. This is to acknowledge that within the system there are parasitic loads such as pumps that move the fluids. These parasitic loads have been explicitly accounted for within this project. The energy streams calculated are at the project boundary. As a result of these parasitic loads, power sales to the grid are not equivalent to the power plant nameplate size.

${ }^{43}$ Most of the "waste" energy is rejected to the atmosphere, but there is also "waste" energy disposed of in waste materials primarily during decommissioning. For simplicity that is considered part of the heat rejected to the atmosphere.
} 


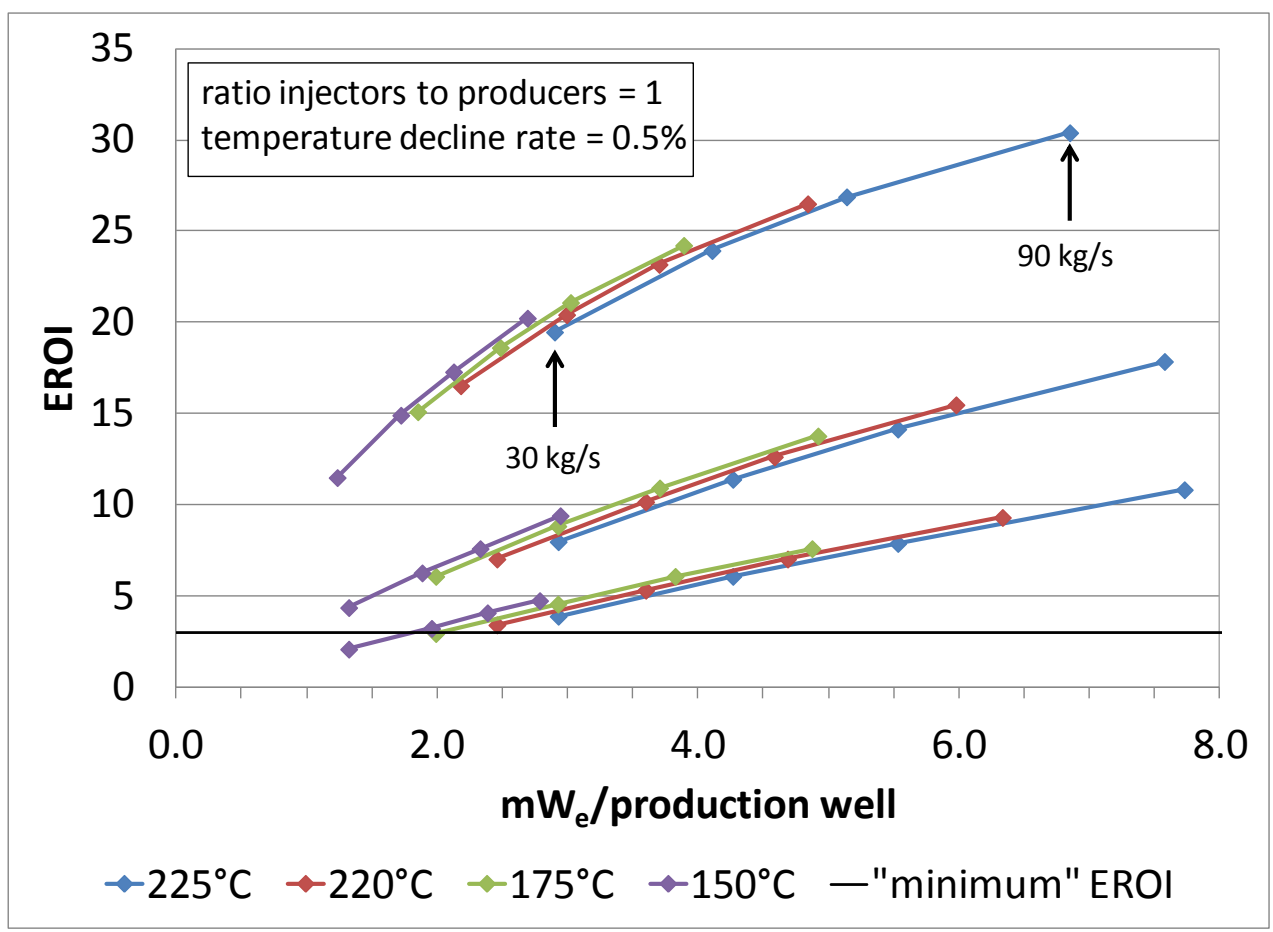

Figure 3: EROI as a function of production well productivity for various well depths, resource temperatures, and production well flow rates. Top set of curves is for $2,000 \mathrm{~m}$, middle $6,000 \mathrm{~m}$, and bottom 10,000m deep wells.

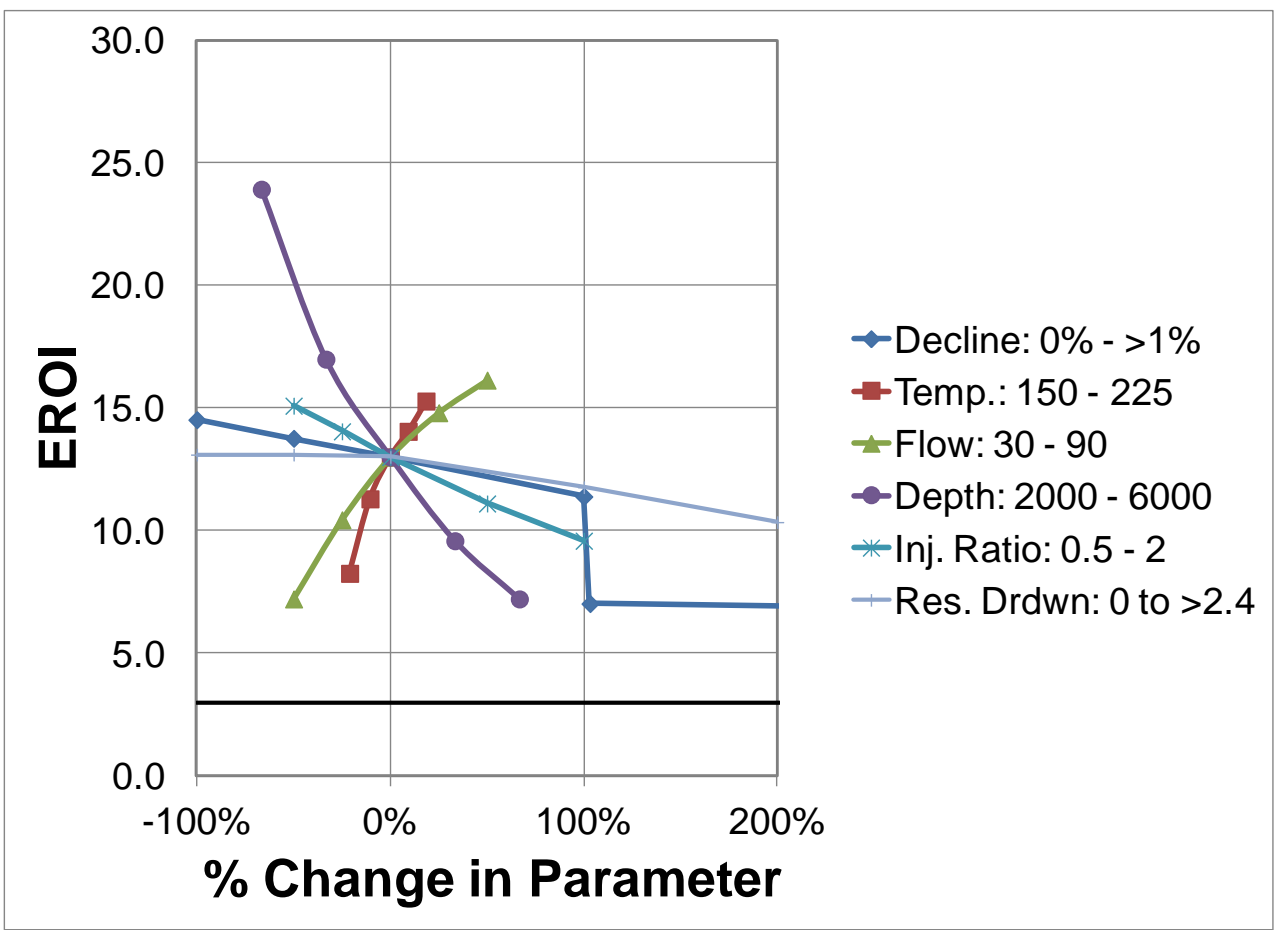

Figure 4: Sensitivity of EROI to parameter changes. ${ }^{44}$ ${ }^{44}$ Horizontal solid line is the "minimum" EROI needed for an energy alternative to be an asset (according to Hall et.
al 2009). 

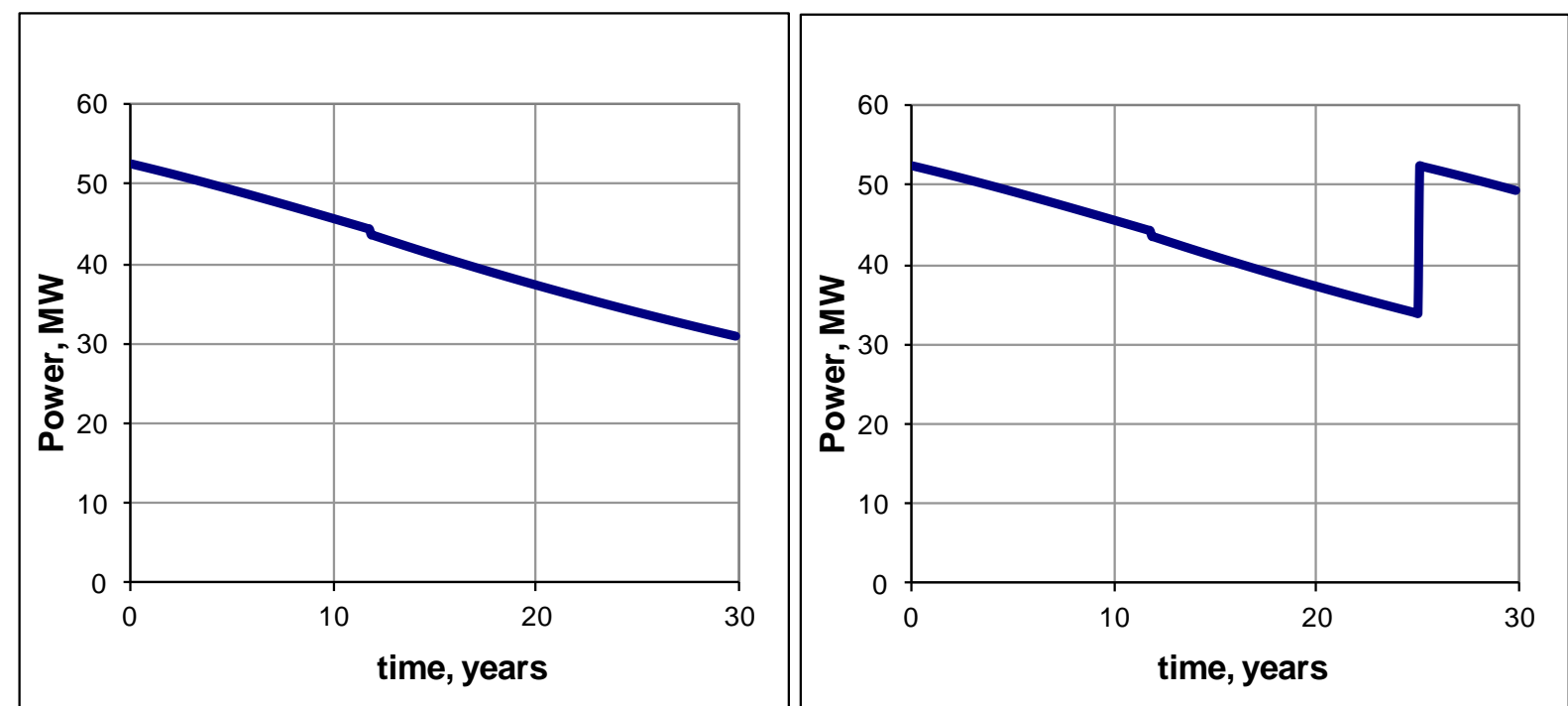

Figure 5: Comparison of net power sales to the grid for a $0.63 \%$ vs. $0.631 \%$ reservoir temperature annual decline rate.

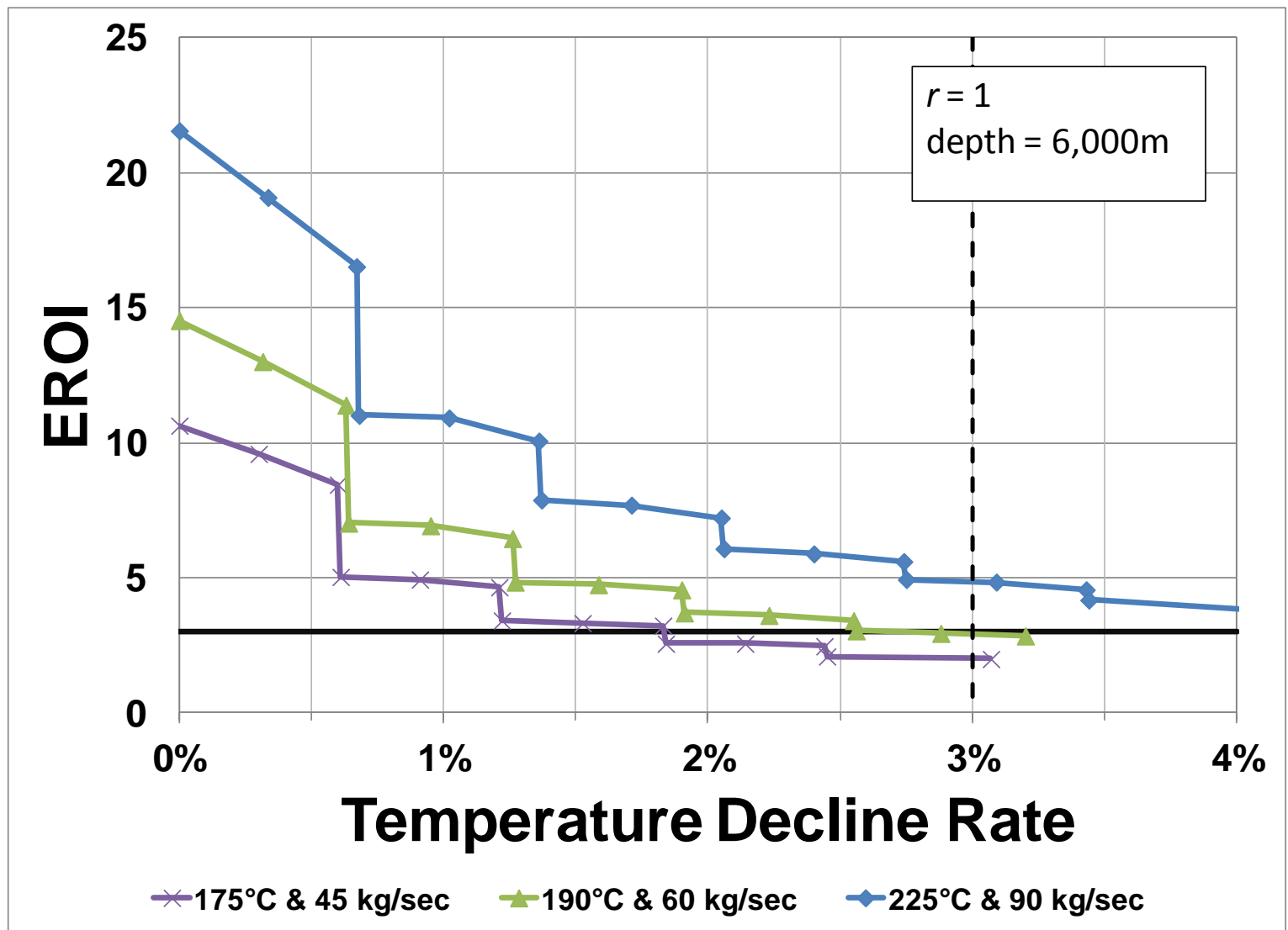

Figure 6: EROI as a function of reservoir temperature annual decline rate for various resource temperatures and production well flow rates. 6,000m deep wells. Vertical dashed line is reservoir temperature decline rate used in The Future of Geothermal. ${ }^{45}$

\footnotetext{
${ }^{45}$ Horizontal solid line is the "minimum" EROI needed for an energy alternative to be an asset (according to Hall et. al 2009).
} 


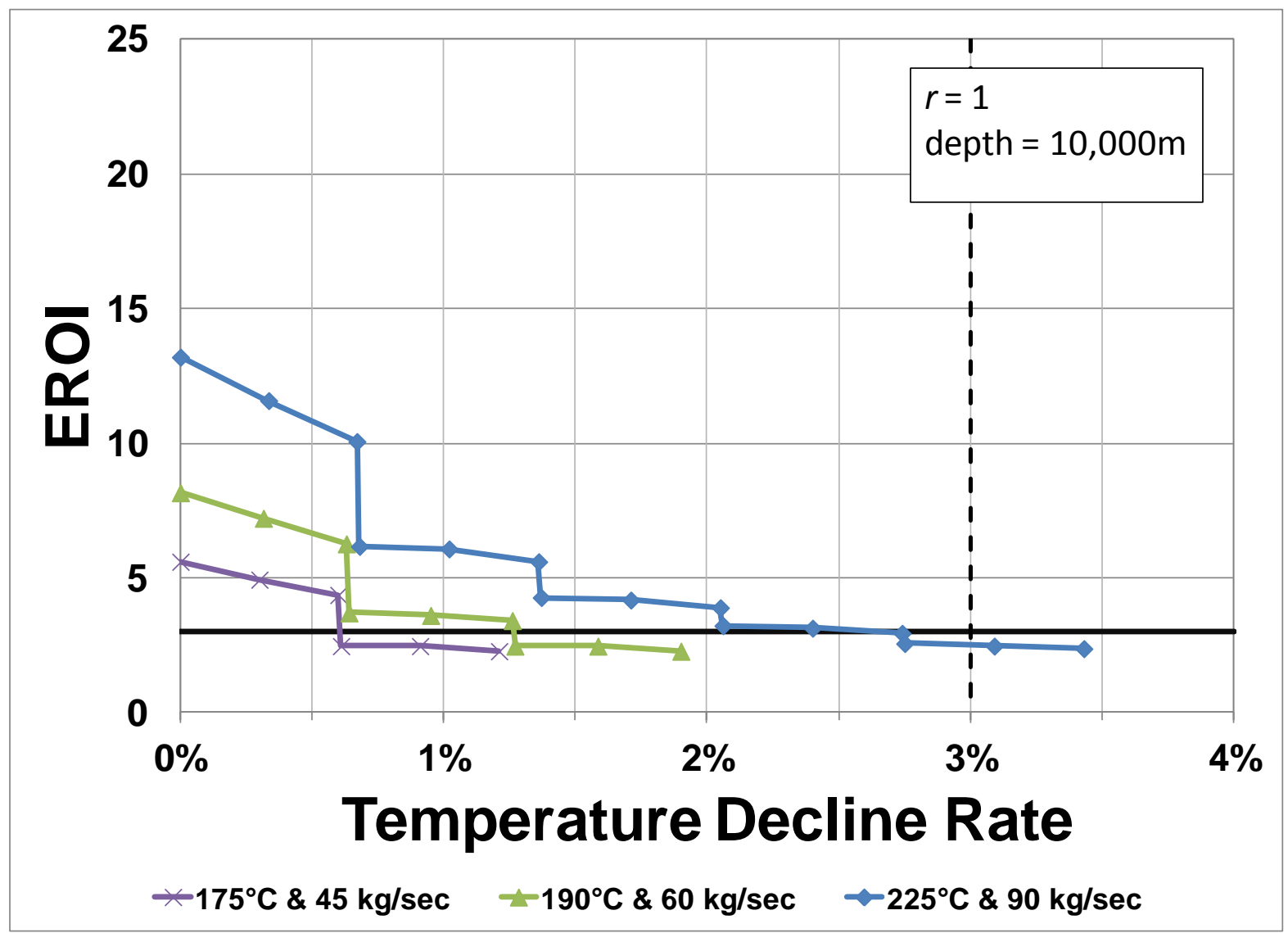

Figure 7: EROI as a function of reservoir temperature annual decline rate for various resource temperatures and production well flow rates. $10,000 \mathrm{~m}$ deep wells. ${ }^{46}$

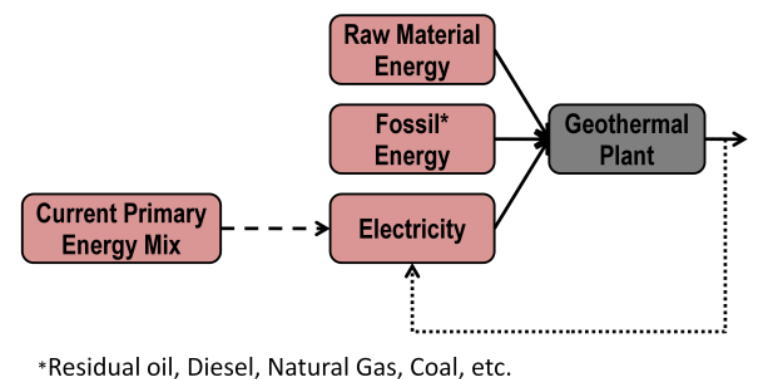

Figure 8: Substitution of geothermal power for current primary energy used to generate electricity.

\footnotetext{
${ }^{46}$ Horizontal solid line is the "minimum" EROI needed for an energy alternative to be an asset (according to Hall et. al 2009).
} 


\section{Tables}

Table 1: Baseline data for sensitivity study.

\begin{tabular}{|l|r|l|}
\hline Resource Temperature & 190 & ${ }^{\circ} \mathrm{C}$ \\
\hline Resource Depth & 6000 & $\mathrm{~m}$ \\
\hline Ratio of Injectors to Producers & 1 & $\mathrm{~N} / \mathrm{A}$ \\
\hline Production Well Flow Rate & 60 & $\mathrm{~kg} / \mathrm{s}$ \\
\hline Annual Rate of Reservoir Temperature Decline & $0.32^{47}$ & $\%$ of Initial Temperature \\
\hline Reservoir Drawdown & 0.8 & $\mathrm{psi}-\mathrm{h} / 1000 \mathrm{lb}$ \\
\hline
\end{tabular}

Table 2: Effectiveness of geothermal power for personal vehicle transportation.

\begin{tabular}{|c|c|c|}
\hline Ways of using diesel & & Relative performance \\
\hline Internal combustion engine & $15 \mathrm{~km} / \mathrm{l}$ & 1.0 \\
\hline Diesel synthesis of hydrogen for fuel cell vehicle ${ }^{48}$ & $13 \mathrm{~km} / \mathrm{l}$ & 0.9 \\
\hline Plug- in electric vehicle powered by central power plant ${ }^{49}$ & $16 \mathrm{~km} / \mathrm{l}$ & 1.1 \\
\hline Investment in geothermal @ EROI of $3^{49}$ & $146 \mathrm{~km} / \mathrm{l}$ & 9.7 \\
\hline Investment in geothermal @ EROI of $13^{49}$ & $634 \mathrm{~km} / \mathrm{l}$ & 42 \\
\hline
\end{tabular}

Table 3: Comparison of traditional heating and cooling vs.geothermal (@EROI of 3 or more).

\begin{tabular}{|l|c|c|c|}
\hline & Traditional & Geothermal & Ratio \\
\hline Diesel furnace & $0.87 \mathrm{~J}$ & $>3 \mathrm{~J}$ & $>3.5$ \\
\hline Electric heating & $0.31 \mathrm{~J}$ & $>3 \mathrm{~J}$ & $>10$ \\
\hline Heat pump heating & $0.74 \mathrm{~J}$ & $>10 \mathrm{~J}$ & $>14$ \\
\hline Heat pump cooling & $1.0 \mathrm{~J}$ & $>13 \mathrm{~J}$ & $>13$ \\
\hline District heating & $1.0 \mathrm{~J}^{50}$ & $>22 \mathrm{~J}$ & $>22$ \\
\hline
\end{tabular}

47 Elsewhere in this study $0.5 \%$ has been used for consistency with other DOE sponsored work, in particular Argonne National Laboratory's LCA (Sullivan et al., 2010).

48 Based on analysis by Bossel (2006).

${ }^{49}$ Calculations previously reported of the $\mathrm{km}$ per liter for an electric plug-in vehicle overlooked the losses associated with charging and storing energy in the vehicle battery which have been reported to be $14 \%$ by Helms et al. (2010).

${ }^{50}$ The point of measurement is at consumption, thus distribution looses in delivering diesel fuel is not considered in this scenario. 


\section{APPENDIX}

The first step in developing a Process Energy Analysis of the energy embodied ${ }^{51}$ in wellfield construction is to establish an inventory of the significant materials and then estimate the energy needed to "assemble" the materials. The materials with the most embodied energy are the casings, cement, and drilling fluids. Other potentially important materials are the pipelines, downhole pumps, bits, and wellhead. The energy to "assemble" the materials includes that embodied in the drilling rig, the fuel to operate the rig, the energy to construct the pipelines, and fuel to haul materials to the location.

To establish a baseline well, the work by ThermaSource for Sandia National Laboratories (Polsky et al., 2008 and Polsky et al., 2009) has been used. The key information in that work is the casing design and bit program (Figure A1) which includes a complete casing specification including weight per foot by grade and lengths including overlap. ThermaSource's cement specifications included cement type, cement volumes (including excess, lead, and tail), and spacer volumes. Thus this well design includes more than adequate detail to determine the material inventory of the significant materials.

The calculations of this project were performed almost entirely in spreadsheets. The spreadsheets are archived as values only, not formulas, in DOE's Geothermal Data Repository. This has been done to encourage independent verification of the calculations rather than continued propagation of any errors in the formulas of the spreadsheets. In general the calculation of Energy Return On Investment (EROI) flows from determining the inventory of materials needed to locating embodied energy per unit material, ${ }^{52}$ and then to compiling the information.

The spreadsheets used are as follows:

1. Well Designs,

2. Parameters,

3. Haulage, and

4. Well Construction Summary.

Discussions of each of the spreadsheets follow. Additional topics discussed to explain calculations include:

1. Drilling Fluid Materials,

2. Other Steel (Bits, Wellheads, \& BOPs),

3. Stimulation,

4. Fuel Usage,

5. Electrical Submersible Pumps,

6. Pipeline,

7. Power Plant, and

\footnotetext{
${ }^{51}$ Embodied energy is a detailed bookkeeping summing up energy inputs from raw material mining through the chain of manufacturing to delivering and disposing a finished product.

${ }^{52}$ The available energy needed to make (starting with mining raw materials), operate, and decommission a product or system.
} 


\section{GETEM.}

\section{Well Designs}

To develop the methodology for estimating material inventories, work by ThermaSource for Sandia National Laboratories (Polsky et al., 2008 and Polsky et al., 2009) has been used. ${ }^{53}$ Key information in that work is the casing design (Figure A1). To allow the embodied energy to be estimated for depths other than that assumed by ThermaSource $(20,000 \mathrm{ft}$ or $6.1 \mathrm{~km})$ that work has been supplemented with information from Sandia National Laboratories. The latter is based on work by Bill Livesay (Encinitas, CA) using WellCost Lite (Mansure et al., 2005). Some of these well designs correspond to actual WellCost Lite analyses performed by Bill Livesay for "The Future of Geothermal" study (Tester, 2006). To support Argonne National Laboratories Life Cycle Assessment (LCA) of geothermal development (Sullivan 2010), well designs were developed for Argonne's scenarios 3 and 4 by modifying WellCost Lite analyses to fit the depths of Argonne's scenarios.

The fuel consumed drilling a well depends upon how long it takes to drill the well. For the well designs developed for "The Future of Geothermal" study, Bill Livesay estimated time to drill each well. For the well designs developed by adapting WellCost Lite designs, the time to drill was estimated from a regression of wells designed for the "The Future of Geothermal" study (Figure A2).

\section{Parameters}

Important to a valid determination of EROI is using a consistent set of inputs. ${ }^{54}$ Input parameters such as embodied energy change as reference work is updated. To facilitate consistent use and updating of input parameters, a set of spreadsheets labeled "Parameters" has been used. These spreadsheets record and document significant input parameters calculations other than change of units are not done in these spreadsheets. Other spreadsheets link to the parameters recorded here. Thus changing an input in these "Parameter" spreadsheets changes its value throughout the calculation of geothermal EROI.

Some input parameters such as distances are found in the haulage spreadsheet.

Input parameters are designated in the spreadsheets by grey background cells.

\section{Haulage}

Haulage has been calculated for the rig, casing, other steel (BOP, wellhead, bits, etc.), surface piping, water, cement, drilling fluid materials, and fuel. The rig assumed, National 1625 mobilization and demobilization was assumed to be amortized over the drilling of 16 wells. Haulage distance for the rig, other steel, cement, and drilling fluid materials was assumed to be Bakersfield to Reno plus 100 miles. Haulage distance for the casing and pipeline was assumed to be Port of Los Angeles to Reno plus 100 miles. Fuel and water were assumed to be available locally 50 miles from the site. Water haulage includes drilling fluid, pipeline construction, and

\footnotetext{
${ }^{53}$ Well Design: Clear Lake CA 20,000 ft EGS Well

${ }^{54}$ Every place where a particular input is used, it should have the same value.
} 
hydrofracing water. Water in cement was assumed to be part of cement (hauled with cement dry goods).

All distances were assumed to be round trips; however, since the rig and BOP's would be returned to Bakersfield and the end of the project, two round trips were assumed for these items, one at the beginning of the project and one after 16 wells have been drilled.

\section{Well Construction Summary}

The spreadsheet Well Construction Summary calculates the embodied energy for each of the wells in the Well Designs spreadsheet. In the Well Construction Summary spreadsheet the values for mass of casing steel and Portland cement and the volume of drilling fluid and rig fuel are linked in from the Well Designs spreadsheet. The mass of Bentonite and drilling fluid polymers is calculated from the volume of drilling fluid as described in the following Drilling Fluid Materials section. The fuel needed for haulage is calculated from amount of casing, drilling cement, and drilling fluid. The pipeline steel, cement, and fuel, as well as, the ESP steel and stimulation energy are fixed inputs independent of the well design.

Figure A3 shows the total well construction embodied energy as a function of well depth for the various well designs described above. On the figure is line showing a trend line fit to the data points as well as the equation of the line:

$$
\mathrm{TJ}=0.0000000983 * \text { Depth }^{2}+0.00272 * \text { Depth }+13,
$$

where $T$ is the prefix Tera and $\mathrm{J}$ is Joules. This equation together with the number of wells and power plant embodied energy is used for parametric studies of EGS EROI.

\section{Drilling Fluid Materials}

To develop the methodology for estimating material inventories, work by ThermaSource for Sandia National Laboratories (Polsky et al., 2008 and Polsky et al., 2009) has been used. Key information in that work is the casing design (Figure A1).

Drilling fluid recipes for the ThermaSource well plan were provided by ChemTech Services ${ }^{55}$ (a division of ThermaSource). Table A1 summarizes materials for each section of the well assuming mid-range $\mathrm{ppb}^{56}$ values. The $\mathrm{ppb}$ of materials for each drilling interval was selected by ChemTech Services to provide the required drilling fluid properties at temperature considering the length of time to drill each interval. Figure A4 shows a surprisingly close correlation between the between the additional drilling fluid required for each interval and the volume of each interval. This correlation is essentially the same as that reported by EPA (1981). The value of this correlation is that, if the drilling fluid volume is not known, it can be estimated from the casing design and bit program of the well. ${ }^{57}$

\footnotetext{
${ }^{55}$ Document: “MUD PROGRAM FOR SANDIA.pdf” provided by Ron Tate of ChemTech Services 11/20/2009.

${ }^{56} \mathrm{ppb}$ : pounds $(0.454 \mathrm{~kg}$ ) per barrel (42 gal).

${ }^{57}$ Estimating the total drilling fluid required for the ThermaSource well from the casing design would result in a $1.6 \%$ error in the volume of drilling fluid needed.
} 
The calculations in Table A1 provide more detail and are more complex than is desirable for calculating embodied energy for a range of well designs and well depths. What are needed are simple rules of thumb that can be used to calculate the masses of the most significant drilling fluid components directly from the total volume of drilling fluid.

Gelex, Polypac, Xanthum Gum, Polymeric Dispersant, and High Temp Stabilizer in Table A1 are all polymeric materials. Lacking information on embodied energy per unit material of these materials individually, they have been lumped together to use a generic value of embodied energy per unit material for polymeric materials. Modified Lignite Resin could be either a mined product or a wood pulp byproduct. If this material is a byproduct, what portion of the manufacturing energy burden should be assigned to it is debatable. For purposes of this study, it has been assumed to be a mined material. ${ }^{58}$

To provide guidance on what are the most significant well construction components, Table A2 is provided as a summary of estimates of well construction embodied energy as of December 2010 (Mansure, 2011). Steel, Portland cement, silica flour, fuel, and other are provided as context for the drilling fluid components. The organic drilling fluid additives are more significant than the other drilling fluid components contributing more than $2 \%$ to the energy needed to construct the well. This is twice the $1 \%$ cutoff chosen for this project. ${ }^{59}$ Bentonite, soda ash, and modified lignite/resin ${ }^{60}$ together contribute significantly less than $1 \% .{ }^{61}$

The ppb of Bentonite required decreases with the downhole temperature. The average Bentonite ppb for the ThermaSource well design was 20. This is the same value as recommend by Halliburton for geothermal mud up to $200^{\circ} \mathrm{C}^{62} \mathrm{~A}$ convenient way to account for the combined contributions of Bentonite, soda ash, and modified lignite/resin is to use an "equivalent" quantity of Bentonite of $25 \mathrm{ppb} .{ }^{63}$ This is the same Bentonite concentration needed for upper, cooler part of the well where modified lignite/resin is not needed. Thus the "equivalent" quantity of Bentonite should not be very sensitive to well depth, temperature, and well design and thus $25 \mathrm{ppb}$ is good rule of thumb.

\footnotetext{
${ }^{58}$ In the case of materials like lignite, the embodied energy includes not only energy input into manufacturing, but also chemical energy contained in the material itself. However, lignite is not used as a drilling mud additive because of its chemical energy.

59 The goal of this project is to identify and include all materials that contribute $1 \%$ or more to the embodied energy needed to construct the well.

60 If the modified lignite/resin embodied energy was increased to that of an average polymeric material manufactured from raw materials rather than mined, it would still not contribute $1 \%$ to the total embodied energy needed to construct the well.

${ }^{61}$ Rather than ignore the contributions of these materials which would produce a systematic error, it is proposed to include them.

${ }^{62}$ Email communication from Charles Landis, Technical Director, Halliburton Industrial Drilling Products, Nov. 16 2009.

${ }^{63}$ For the ThermaSource well design this would result in a $0.02 \%$ error in the embodied energy of these products.
} 
The total polymeric ppb recommended by Halliburton for $200^{\circ} \mathrm{C}$ was 7 , slightly more than the $6^{64}$ recommended by ChemTech Services. The polymeric $p p b^{65}$ for the ThermaSource well plan varied from $<0.1$ in the upper, cooler part of the well to 5.25 in the bottom, $300^{\circ} \mathrm{C}$ part of the well. The average polymeric ppb was 1.5 . Thus to be conservative taking into consideration Halliburton's somewhat higher polymeric additive concentrations, an average value $1.75 \mathrm{ppb}$ will be assumed.

\section{Other Steel (Bits, Wellheads, \& BOPs)}

Based on Hughes Christiansen bit catalogs, the total weight of the bits for the ThermaSource well is $\sim 5.3 \mathrm{Mg}$. For comparison this is $\sim 0.4 \%$ of the weight of the casing. However, the impact of the bits on embodied energy will be higher than this percentage implies because the bits are not just steel. They contain tungsten carbide and potentially in the future polycrystalline diamond compacts. Tungsten carbide embodied energy is $400 \mathrm{MJ} / \mathrm{kg}$ (Dahmus and Gutowski, 2004). This is more than $\sim 14$ times the energy embodied into manufacturing steel. However, provided the tungsten carbide is less than $50 \%$ of the weight of the bits, ${ }^{66}$ the embodied energy of the bits will be less than the $1 \%{ }^{67}$ of the cut off target for this project.

The weight of the wellhead has been estimated based on information from Cameron to be $\sim 4.7$ $\mathrm{Mg}$, also $\sim 0.4 \%$ of the weight of the casing. The weight of the BOP's, also estimated based on information from Cameron, is $\sim 112 \mathrm{Mg}$ or $1 \%$ of the weight of the casing. The BOP's would be reused. If they are amortized over 16 wells like the mob and demob of the rig, the effective weight of the BOP's would be $<0.1 \%$ of the weight of the casing.

Furthermore, most of the materials in the bits, wellheads, and BOPs will be recycled reducing the energy impact. Based on the low percentages and recycling the bits, wellheads, and BOPs will not be included in calculating the energy embodied into well construction.

\section{Stimulation}

Two factors govern the energy consumed during simulation of the reservoir: the volume injected and the wellhead injection pressure. Clark et al. (2010) indicate the total water injected could be from $42,200 \mathrm{~m}^{3}$ to $55,400 \mathrm{~m}^{3}$. This is more than the average of stimulation values found in the literature (Asanuma et al., 2004; Michelet and Toksöz, 2006; Zimmermann et al., 2009; Tester, 2006) of 26,939 $\mathrm{m}^{3}$ according to Clark et al. (2010). However, EGS reservoir stimulations conducted to date have yet to provide the connectivity between the injection and production well that is expected to be required to provide adequate reservoir longevity. A recent computer modeling of site specific stimulation of the Newberry resource (Cladouhos et al., 2011) suggests a volume of $83,000 \mathrm{~m}^{3}$ will be required. Considering these various stimulation volumes, Clark et al.'s (2010) upper volume of $55,400 \mathrm{~m}^{3}$ will be assumed.

\footnotetext{
${ }^{64}$ Including modified lignite/resin.

${ }^{65}$ Gelex, Polypac, Xanthum Gum, Polymeric Dispersant, and High Temp Stabilizer.

${ }^{66}$ A reasonable assumption based on visual inspection of drill bits (Orazzini et al. 2011).

67 This conclusion is in contrast to (Herendeen and Plant, 1979) who, based on economic input/output analysis, concluded bits contribute $3.1 \%$ to the well construction embodied energy.
} 
The pressure necessary to stimulate the reservoir is site specific as well as depending upon whether the objective is to increase the permeability of existing natural fractures or create new fractures. Actual injection pressures ramp up as the stimulation progresses; thus an average rather than initial or final pressure is needed for calculating pumping energy. Cladouhos et al.'s (2011) modeling of the Newberry resource implies an average injection pressure of 11 MPa. At Soultz the wellhead pressure required for stimulation was $20 \mathrm{MPa}$ (Baria et al., 2006). At Cooper Basin Australia the pressure needed was 60 MPa (Asanuma et al., 2004), but 35 MPa of that was to overcome the artesian overpressure at that site (Tester, 2006). Assuming that the typical EGS site will not have an overpressure, $20 \mathrm{MPa}$ has been assumed as the stimulation pressure.

Efficiency of the triplex pumps used for hydrofracing is $85 \% .{ }^{68}$ Typical efficiency of the diesel engine powering the triplex pumps is $32 \% .{ }^{69}$ Thus the overall efficiency of the stimulation system is $\sim 27 \%{ }^{70}$

For this work it has been assumed that there will be "one" ${ }^{\text {71 }}$ stimulation per well and that both producers and injectors will be stimulated.

Based on the volume, pressure, and efficiency above, the energy required to stimulate is $4.1 \mathrm{TJ}$ per well.

\section{Fuel Usage}

The formula used for diesel fuel consumption by Bill Livesay in WellCost Lite is 0.65 gal/hp-hour. This corresponds to a duty cycle of $\sim 50 \%$ on a typical diesel prime mover used on drill rigs.

Bob Swanson in the ThermaSource work for Sandia National Laboratories (Polsky et al., 2008 and Polsky et al., 2009) assumed 2,500 gal/day for a 3,000 hp rig. This estimate was based on fuel usage of 1800 to 2000 gallons per day while drilling 10,000' to 12,000' wells at The Geysers. Since the work for Sandia assumed a bigger rig with a top drive, the fuel consumption was increased to 2,500 per day. However, the wells drilled at The Geysers included an air package consisting of three $1000 \mathrm{hp}$ compressors and a $1000 \mathrm{hp}$ booster. ${ }^{72,73}$ An air package will not be needed for the typical EGS well. Fuel consumption at The Geysers when the air package was not being used was consistent with Bill Livesay's formula in WellCost Lite.

\footnotetext{
${ }^{68}$ Based on an OFM 2000 triplex pump operating at $330 \mathrm{rpm}$ outputting $970 \mathrm{gpm}$ (61 l/sec or $23 \mathrm{bbl} / \mathrm{min}$ ).

${ }^{69}$ Based on a Caterpillar 3512 B operating at $50 \%$ full load.

${ }^{70}$ Energy is needed for stimulation system haulage and also energy is embodied into the manufacturing of the stimulation system; however this is less than $1 \%$ of the energy consumed during pumping and thus is insignificant compared to uncertainty in estimating the efficiency of the stimulation system.

${ }^{71}$ It is assumed that the volume $55,400 \mathrm{~m}^{3}$ is a total for the well for all the zones within the well that are stimulated.

72 The air package was used about one third of the time.

${ }^{73}$ Email communication from Bob Swanson, 11/5/2009.
} 
Total fuel consumption depends both on the fuel consumption rate and the number of days to construct the well. The objective of well construction is to minimize cost subject to the design and safety requirements. There are different strategies to minimize cost: sometimes extra time and equipment are used in an effort to minimize material costs (this approach was an important consideration in Bob Swanson's work); sometimes emphasis is on minimizing costs by minimizing the time to construct the well (this approach was an important consideration in Bill Livesay's work for The Future of Geothermal - Tester, 2006).

For a $6 \mathrm{~km}$ well in the same geologic setting, Bob Swanson assumed 10\% longer to drill the well than Bill Livesay. Considering the variability that one expects when drilling geothermal wells (Mansure et al., 2006), 10\% is very good agreement. However, the geologic setting assumed by Bob Swanson in the ThermaSource work is more challenging than expected for a typical EGS well. Thus the time estimated by Bob Swanson for the ThermaSource well is $\sim 30 \%$ more than Bill Livesay's typical well for The Future of Geothermal study.

In conclusion, while The ThermaSource well used to develop the methodology for this project assumes more fuel than Bill Livesay's work for The Future of Geothermal (Tester, 2006), Livesay's fuel consumptions will be used as it allows the determination of fuel consumption as a function of depth.

\section{Electrical Submersible Pump (ESP)}

Information on the materials for the production well electrical submersible pump (ESP) was provided by Hydro Resources. ${ }^{74}$ Materials for the ESP are divided into those dependent on the size of the pump and those that depend on the depth at which the pump is set. ${ }^{75}$ The former include motors, seals, pump, motor lead cable, and discharge assembly. For convenience these are labeled ESP-fixed. The latter category includes the power cable, banding, and column pipe. These are labeled ESP-per-foot. The quantity of materials in the ESP of course depends upon the flow rate and pressure head of the pump. These parameters need to be chosen trading off the productivity of the reservoir and power available from the power plant to run the pumps.

A estimate of the materials and embodied energy of an ESP was reported at the Stanford Geothermal Workshop 2011 (Mansure, 2011). For this estimate a $950 \mathrm{gpm}, 1,000 \mathrm{hp}$ ESP set at 3,200 ft was assumed. Table A3 summarizes the ESP-fixed materials and Table A4 summarizes the ESP-per-foot materials for this ESP.

Table A5 summarizes the materials and embodied energy needed for this example ESP. ${ }^{76}$ ESP designs vary with resource and well design; however, the pump setting depth does not necessarily change with well depth. Table A5 shows that excluding the steel, the example ESP contributes less than $0.2 \%$ of the embodied energy. When the production pipe is included, the ESP contributes $\sim 1.0 \mathrm{TJ}$ to the energy needed to construct a production well. ESPs are not

\footnotetext{
${ }^{74}$ Email communication from Randy Badger, 4/5/2010.

${ }^{75}$ Diameter of the pipe used may also be important, but not considered in this work.

${ }^{76}$ Note: there is a typographical error in the table of the appendix of the Mansure (2011). The embodied energy of copper should be $0.095 \mathrm{TJ}$ not $0.01 \mathrm{TJ}$.
} 
required for injection wells. Thus considering the well field as a whole, ESPs contribute less than the $1 \%$ cut-off assumed in this project.

The pump setting depth could be greater than 3,200 ft. A limiting factor sizing and choosing pump setting depths for ESPs is the power consumed by the pump. Setting the pump deeper will normally increase the power required. Unless the deeper well produces significantly more thermal power, there is not necessarily a benefit of deepening the well to set the pump deeper. For this project a fixed burden of $38.6 \mathrm{Mg}$ of steel per well for ESPs has been assumed. ${ }^{77}$

\section{Pipeline}

The materials needed for the wellfield pipeline include: steel (for pipeline, supports, and rebar), Portland cement, aggregate, forming tube (cardboard form for pouring the concrete), insulation (assumed for production wells, but not injection wells), water, and fuel. Based on work by Argonne National Laboratory for their Life Cycle Assessment (LCA) of geothermal power production, the materials per well for the pipeline are summarized in Table A6. Assumptions are described in greater detail in two Argonne reports (Sullivan et al., 2010 and Clark et al., 2010) and include $500 \mathrm{~m}$ of pipeline per well.

Neither cardboard nor insulation (Table A6) contribute significantly $(>1 \%)$ to the embodied energy. The Portland cement embodied energy in the pipeline is also less than $1 \%$, but since Portland cement for casing wells is significant, the pipeline contribution is included in well construction embodied energy calculations. The embodied energy in pipeline steel is significant.

\section{Power Plant}

The energy embodied into the power plant has been calculated from the work of Sullivan et al. (2010). From the $\mathrm{mt} / \mathrm{MW}$ of materials in Table A2a of Sullivan et al. and the embodied energy per mt in GREET (Burnham et al., 2006) 14.55 TJ of input energy is needed per MW for the 20 MW EGS case and 13.32 TW/MW for the $50 \mathrm{MW}$ case. The higher number has been used to be conservative. At the 2nd Quarter Geothermal Analysis Forum February 24, 2011, Sullivan et al. reported that in addition to the indirect input energy reported in Sullivan et al. (2010) an additional $12 \%$ direct (energy actually consumed during building construction) needs to be added to the power plant energy input to be conservative. ${ }^{78}$ Thus for a $50 \mathrm{MW}$ power plant (baseline considered in this work) the input energy is

$$
(50 \mathrm{MW}) *(14.55 \mathrm{TJ} / \mathrm{MW}) *(1+12 \%)=815 \mathrm{TJ} \text {. }
$$

\section{GETEM}

The net energy sold to the grid over the life of the project and the number of wells required have been determined using GETEM (Entingh and Mines, 2006; Mines, 2008). GETEM is the Geothermal Electricity Technologies Evaluation Model, an Excel spreadsheet for calculating geothermal energy costs. The version used is the March 2011 release. Calculations of this

\footnotetext{
${ }^{77}$ Since only the production well requires an ESP this is twice the actual material needed. This has been done to be conservative.

${ }^{78} 12 \%$ is not added to the wellfield input energy since the fuel needed to construct the well field is explicitly included in the Well Construction Summary spreadsheet.
} 
version were compared to the version used for Argonne National Laboratory's LCA of geothermal development (Sullivan 2010) for consistency in the number of wells needed. For consistency with the LCA and needs of this project several of the default input values in GETEM were changed. Inputs that were changed from default are listed in Table A7 Also listed in the table are the input parameters that were varied as part of this study and the output results used to calculate EROI.

The "Design Temperature for EGS Plant" was set to $10^{\circ} \mathrm{C}$ less than the resource temperature. The "Potential Resource Found" was set high enough that as the annual reservoir temperature decline rate was varied there was always adequate resource for replacement wells. Exploration and confirmation wells were not considered in calculating EROI, thus the extra exploration and confirmation wells resulting from the high resource potential were not a factor in results. Exploration and confirmation wells were not considered under the assumption the ultimate resource size was large resulting in the amortization of exploration and confirmation wells over a large number of power plants. ${ }^{79}$ The "Number of Well Tests" was set high enough eliminate errors not related to the calculation of power sales to grid and number of production wells.

GETEM discounts power sales to grid since future sales are of less economic value than current sales. To determine the actual total energy output to the grid, not discounting future power sales, the "Discount Rate for Makeup Calculations" was set to zero. This changes the economic calculations done by GETEM, but not the results required to calculate EROI. ${ }^{80}$ GETEM reported power sales to grid does not account for utilization factor; it is included into the economic calculations in GETEM. Thus to calculate energy to grid, utilization factor must be included.

For each result calculation the Brine Effectiveness was estimated by triggering the equation solver in the Binary A1 worksheet of GETEM and the result accepted. Before recording results it was verified that GETEM did not trigger any error flags.

\footnotetext{
${ }^{79}$ In calculating levelized cost of power sales this assumption would not be appropriate because of the upfront nature of exploration and confirmation well drilling costs.

${ }^{80}$ The same resultant levelized power to grid can also be obtained averaging the monthly power sales, but that is more cumbersome to do.
} 


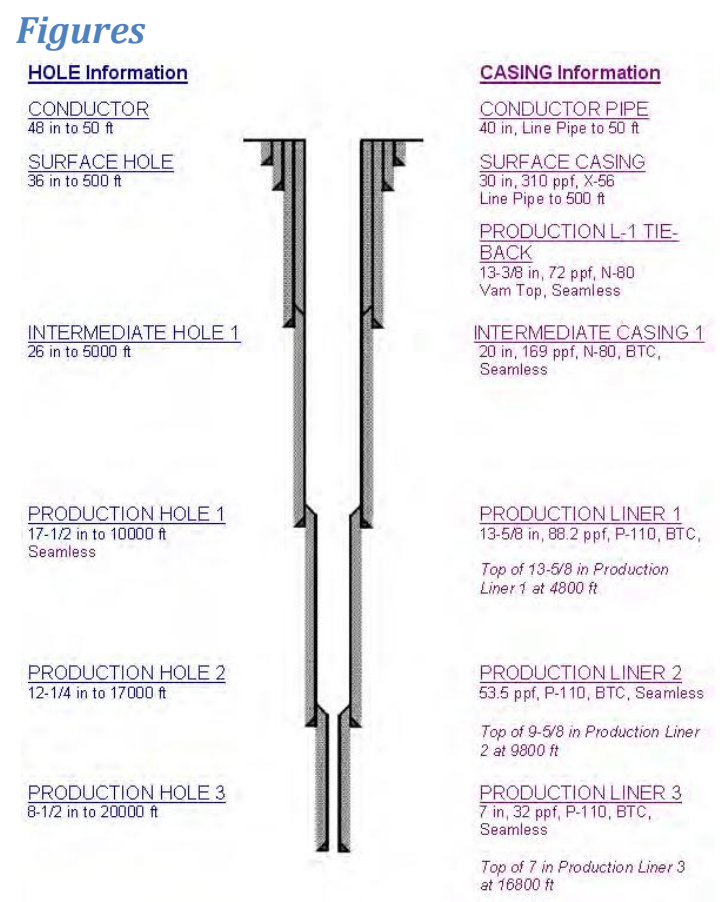

Figure A1: Casing specification for the well design assumed by ThermaSource.

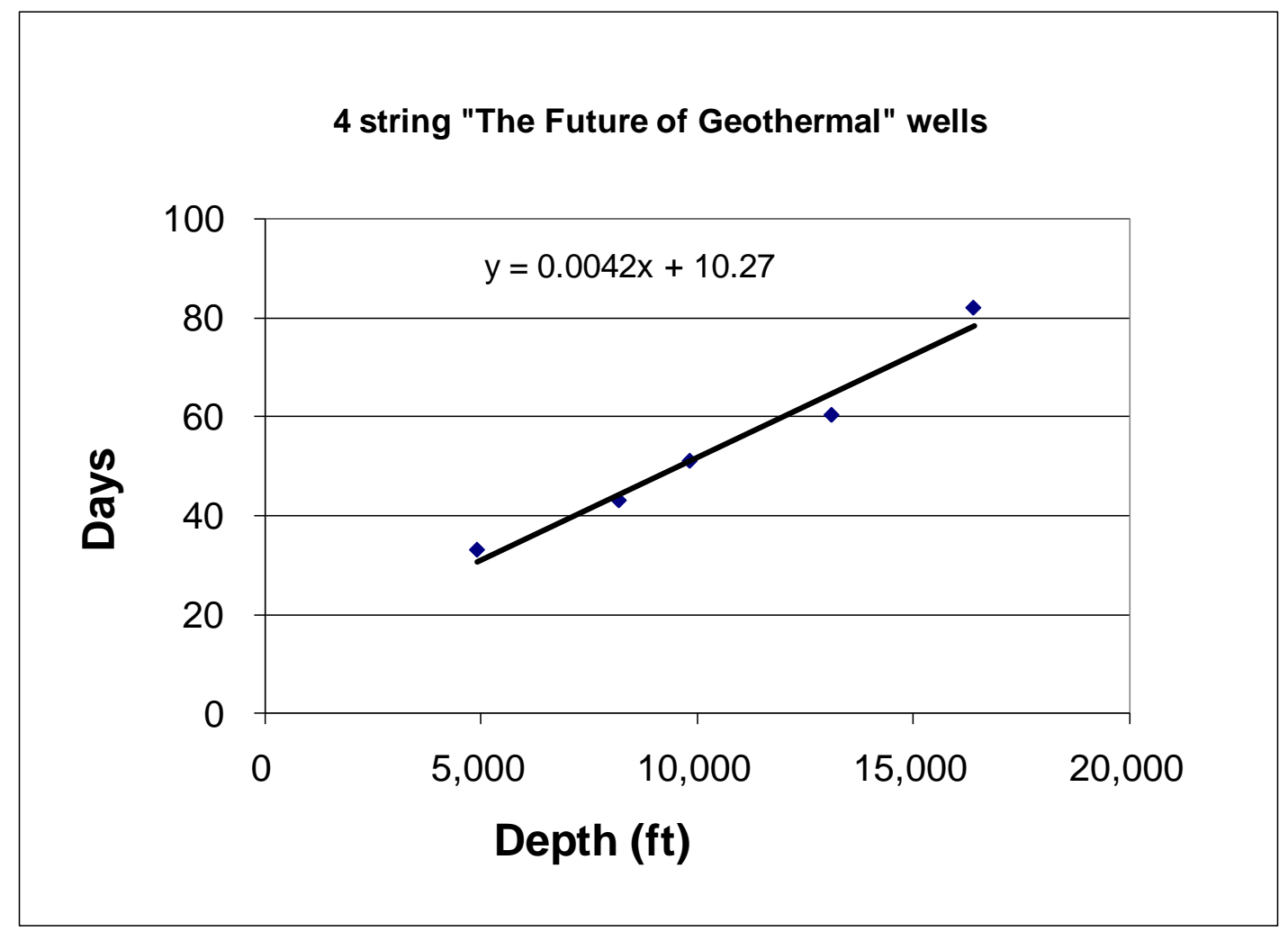

Figure A2: Drilling time vs. well depth. 


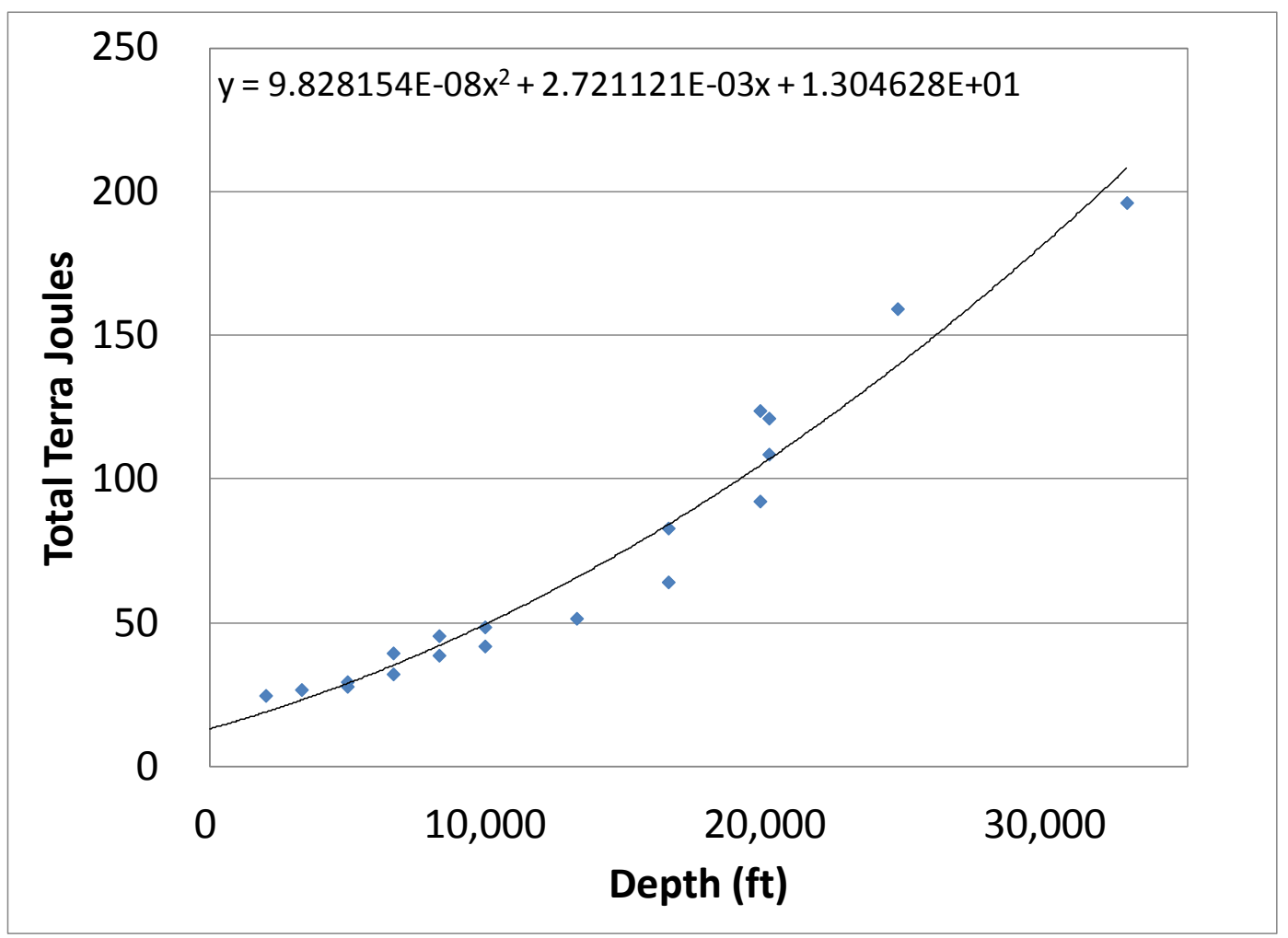

Figure A3: Total Well Construction Embodied Energy as a Function of Depth.

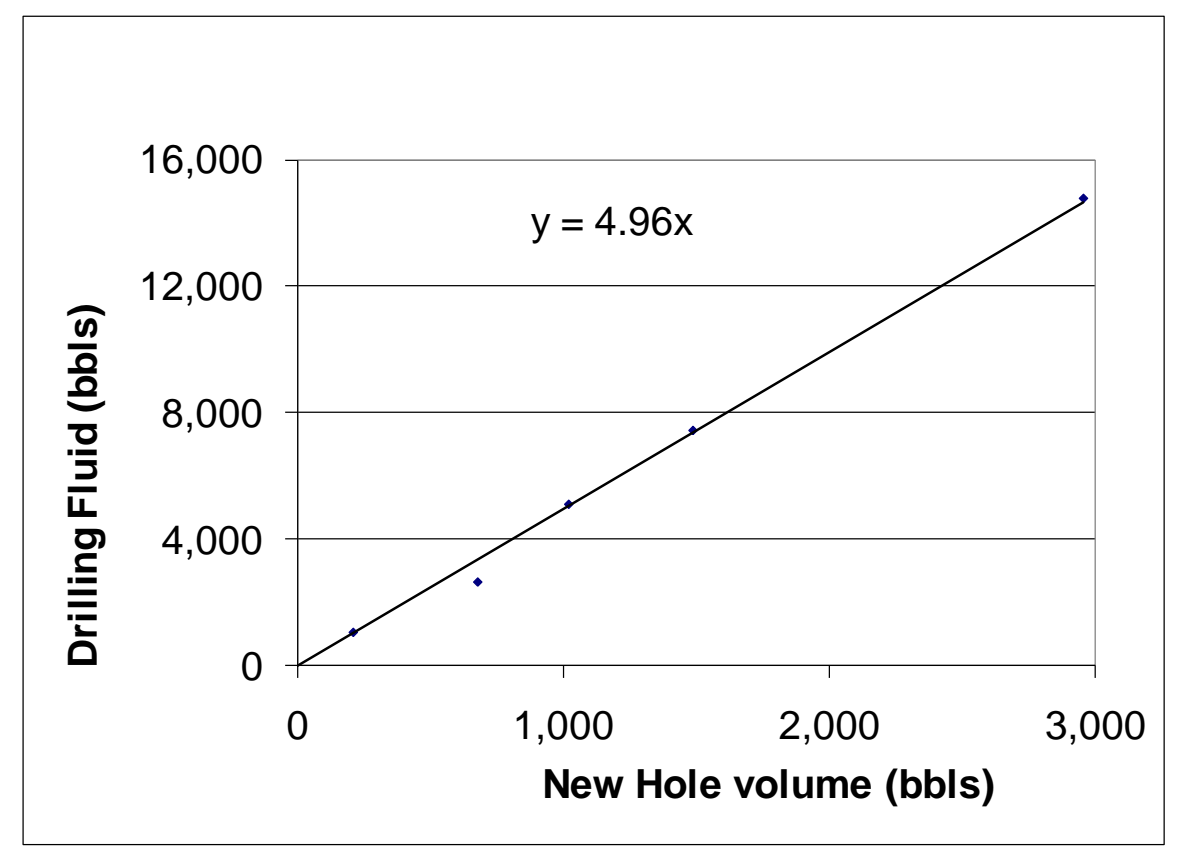

Figure A4: Correlation between hole volume of each interval and additional drilling fluid required. 


\begin{tabular}{|c|c|c|c|c|c|c|c|c|c|c|}
\hline Casing Schedule & 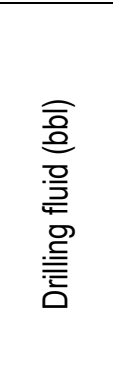 & 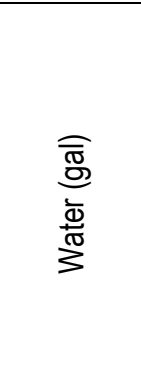 & 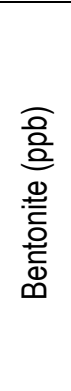 & $\begin{array}{l}\frac{a}{0} \\
\frac{0}{2} \\
\frac{1}{0} \\
\frac{\pi}{8} \\
\infty\end{array}$ & 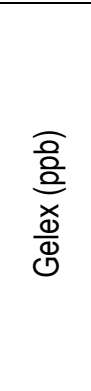 & 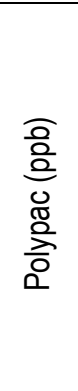 & 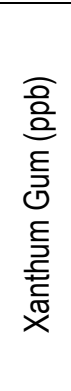 & 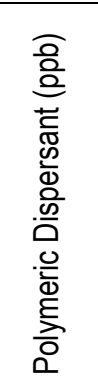 & 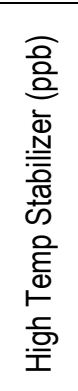 & 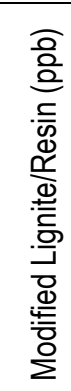 \\
\hline Surface Casing & 2,645 & 111,090 & 25 & 0.50 & 0.08 & & & & & \\
\hline Intermediate Casing & 14,781 & 620,802 & 23 & 0.38 & & 0.75 & 0.38 & & & \\
\hline Production Liner \#1 & 7,440 & 312,480 & 18 & 0.25 & & 0.75 & 0.38 & 0.04 & 0.04 & 0.08 \\
\hline Production Liner \#2 & 5,104 & 214,368 & 14 & 0.25 & & 1.00 & 0.50 & & 1.5 & 3 \\
\hline Production Liner \#3 & 1,053 & 44,226 & 11 & 0.25 & & 1.5 & 0.75 & & 3 & 1.5 \\
\hline Total (bbl) & 31,023 & & & & & & & & & \\
\hline Total (gal) & & $1,302,966$ & & & & & & & & \\
\hline Total (Mg) & & & 280 & 4.66 & 0.096 & 10.6 & 5.30 & 0.127 & 5.03 & 7.91 \\
\hline
\end{tabular}

Table A1: Drilling fluid volumes, masses, and composition.

\begin{tabular}{|c|c|c|c|c|c|c|c|c|c|}
\hline & $\begin{array}{l}\bar{\Phi} \\
\Phi \\
\dot{\Phi}\end{array}$ & 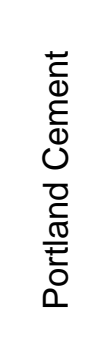 & $\begin{array}{l}\overline{\bar{y}} \\
\frac{0}{4} \\
\frac{\mathbb{O}}{\overline{\bar{\omega}}}\end{array}$ & 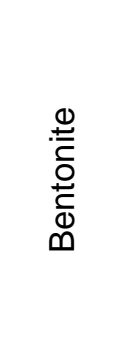 & $\begin{array}{l}\frac{c}{\infty} \\
\frac{\pi}{0} \\
\frac{\pi}{0} \\
\infty\end{array}$ & 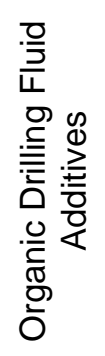 & 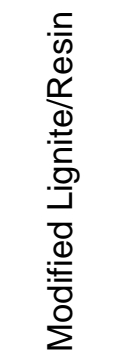 & $\begin{array}{l}\bar{\Phi} \\
\vec{\Psi}\end{array}$ & $\begin{array}{l}\frac{\searrow}{\Phi} \\
\stackrel{ \pm}{ \pm}\end{array}$ \\
\hline \% Energy & $38.8 \%$ & $5.8 \%$ & $0.04 \%$ & $0.43 \%$ & $0.07 \%$ & $2.1 \%$ & $0.02 \%$ & $52.2 \%$ & $0.6 \%$ \\
\hline
\end{tabular}

Table A2: Well construction embodied energy percentages for the ThermaSource well design.

\begin{tabular}{|c|c|c|c|c|c|}
\hline $\begin{array}{c}\text { Steel } \\
(\mathrm{Mg})\end{array}$ & $\begin{array}{c}\text { Copper } \\
(\mathrm{Mg})\end{array}$ & $\begin{array}{c}\text { Brass } \\
(\mathrm{Mg})\end{array}$ & $\begin{array}{c}\text { Lead } \\
(\mathrm{Mg})\end{array}$ & $\begin{array}{c}\text { Oil } \\
(\mathrm{Mg})\end{array}$ & $\begin{array}{c}\text { Rubber } \\
(\mathrm{Mg})\end{array}$ \\
\hline 2.15 & 1.13 & 0.640 & 0.001 & 0.02 & 0.013 \\
\hline
\end{tabular}

Table A3: ESP fixed materials. 


\begin{tabular}{|l|c|c|c|}
\hline & Steel & Copper & Rubber \\
\hline Ibs per foot & 26.58 & 1.36 & 0.71 \\
\hline Total $(\mathrm{Mg})$ & 38.6 & 2.0 & 1.0 \\
\hline
\end{tabular}

Table A4: ESP per foot materials.

\begin{tabular}{|c|c|c|c|c|c|c|}
\hline & $\begin{array}{l}\bar{\Phi} \\
\dot{\Phi}\end{array}$ & $\begin{array}{l}\frac{1}{\Phi} \\
\frac{0}{0} \\
\text { O }\end{array}$ & $\begin{array}{l}\mathscr{D} \\
\stackrel{0}{0} \\
\ddot{\infty}\end{array}$ & $\begin{array}{l}\mathbb{8} \\
\stackrel{\mathbb{\Phi}}{\Phi}\end{array}$ & $\overline{\bar{o}}$ & 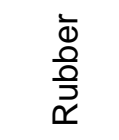 \\
\hline Mass (Mg) & 40.7 & 3.10 & 0.64 & 0.001 & 0.02 & 1.04 \\
\hline \% Energy & $0.90 \%$ & $0.08 \%$ & $0.05 \%$ & $<.001 \%$ & $<.001 \%$ & $0.04 \%$ \\
\hline
\end{tabular}

Table A5: ESP materials and embodied energy.

\begin{tabular}{|c|c|c|c|c|c|c|}
\hline & Steel & $\begin{array}{c}\text { Portland } \\
\text { Cement }\end{array}$ & Cardboard & Insulation & Fuel & Water \\
\hline $\mathrm{Mg}$ & 52.3 & 52.8 & 3.40 & 3.45 & $\left(37.8 \mathrm{~m}^{3}\right)$ & 6,171 \\
\hline TJ & 1.3 & 0.34 & 0.06 & 0.01 & 1.60 & \\
\hline
\end{tabular}

Table A6: Pipeline materials and embodied energy.

\begin{tabular}{|l|c|l|l|}
\hline Non Default Inputs & Value & Units & Location in GETEM \\
\hline Design Temperature for EGS Plant & 180 & ${ }^{\wedge} \mathrm{C}$ & INPUT'!R70 \\
\hline Potential Resource Found & 1000 & $\mathrm{MW}$ & INPUT'!R77 \\
\hline Number of Well Tests & 20 & $\mathrm{n} / \mathrm{a}$ & INPUT'!R181 \\
\hline Discount Rate for Makeup Calculations & 0 & $\%$ & INPUT'!R38 \\
\hline & & & \\
\hline Input Parameter & & & \\
\hline Resource Temperature & 190 & $\wedge$ & \\
\hline Resource Depth & 6000 & $\mathrm{~m}$ & INPUT'!R72 \\
\hline Ratio of Injection Wells to Production Wells & 1 & $\mathrm{n} / \mathrm{a}$ & INPUT'!R73 \\
\hline Production Well Flow Rate & 60 & $\mathrm{~kg} / \mathrm{s}$ & INPUT'!R190 \\
\hline Annual Reservoir Temperature Rate of Decline & 0.5 & $\%$ Initial Temperature & INPUT'!R258 \\
\hline Input Reservoir Drawdown & 0.8 & $\mathrm{psi}-\mathrm{h} / 1000 \mathrm{lb}$ & INPUT'!R246 \\
\hline & & & \\
\hline Results & & & \\
\hline Levelized Power to Grid & 43.7 & $\mathrm{MW}$ & Binary Output'!D24 \\
\hline Utilization Factor & 95.0 & $\mathrm{n} / \mathrm{a}$ & INPUT'!R34 \\
\hline Initial Production Wells & 10.7 & $\mathrm{n} / \mathrm{a}$ & Binary Output'!D42 \\
\hline Number of Times Flow Loops Replaced & 0 & $\mathrm{n} / \mathrm{a}$ & Reservoir B1'!I424 \\
\hline Errors & 0 & $\mathrm{n} / \mathrm{a}$ & INPUT'!R26 \\
\hline
\end{tabular}

Table A7: Non default GETEM inputs, input parameters, and results. 